\title{
Prognostic Serum Factors in Traumatic Brain Injury: A Systematic Review
}

Firooz Salehpoor ${ }^{1}$, Ali Meshkini ${ }^{1}$, Ghaffar Shokouhi ${ }^{1}$, Javad Aghazade ${ }^{1}$, Iraj Lotfinia ${ }^{1}$, Moslem Shakeri ${ }^{1}$, Mohammad Shimia ${ }^{1}$, Alireza Razzaghi ${ }^{2}$, Farhad Mirzaee ${ }^{1}$, Atta Mahdkhah ${ }^{{ }^{*}}$

${ }^{1}$ Department of Neurosurgery, Tabriz University of Medical Sciences, East Azarbaijan, Iran

${ }^{2}$ Guilan Road Trauma Research Center, Poursina Hospital, Guilan University of Medical Sciences, Guilan, Iran

${ }^{*}$ Corresponding Author: Department of Neurosurgery, Tabriz University of Medical Sciences, East Azarbaijan, Iran Tel:+989144039122, Fax:+04133340830, Email: mahdkhah@yahoo.com

\section{Abstract}

Background \& Aim: Traumatic brain injury is one of the main causes of death and disability. The aim of this study is to systematically review the articles which assessed some serum factors of traumatic brain injury patients in relation to their outcomes.

Methods \& Materials/Patients: Databases were searched for relevant publications from 2005 to 2014. Selection criteria were:Studies which evaluate the factors affecting the outcome after TBI, TBI defined as "acute changes in brain function resulting in a strong external force to the head". Resultswere measured by Glasgow Outcome Score or a comparable measure.Factors were measured in first month after injury and the prognosis was addressed. All papers were checked and approved by a specialist and expert in that field. A systematic review was performed for prognostic factors.

Results: Sixty-three studies were included. Most studies used Glasgow Outcome Score at 6 months post-injury as outcome measure, sometimes in combination with other outcome measures. Strong evidence for predicting outcome was found for serum concentration of S100 protein, NSE, MBP, NF-H, GFAP, UCH-L1, blood glucose levels, serum levels of LDH, sodium level, prothrombin time, partial thromboplastin time, platelet count, D.dimer, HSP 70, serum levels of IL-8, number of circulating EPCs, and DNA levels in serum. Moderate evidence for predicting outcome was found for high serum MMP9. Strong evidence of no association was found for WBC count and serum cortisol levels. Moderate evidence of no association was found for serum total cholesterol for other determinants, inconclusive or no evidence or limited evidence was found.

Conclusion: S100 protein, NSE, MBP, NF-H, GFAP, UCH-L1, blood glucose levels, serum levels of LDH, sodium level, prothrombin time, Partial thromboplastin time, platelet count, D.dimer, HSP 70, serum levels of IL-8, number of circulating EPCs, and DNA levels in serum predicted outcome after traumatic brain injury. WBC count, serum cortisol levels, total cholesterol and MMP9 did not have predictive value.

Keywords: Prognostic; Serum Factors; Traumatic Brian Injury

Please cite this paper as: Salehpoor F, Meshkini A, Shokouhi Gh, Aghazade J, Lotfinia I, Shakeri M, et al. Prognostic Serum Factors in .Traumatic Brian Injury: A Systematic Review. Iran J Neurosurg. 2015;1(1):10-22

\section{Introduction}

Traumatic brain injury still remains a serious concern and one of the leading causes of death and disability, particularly among young adults $(1,2)$. Based on studies of prevention of diseases in United States, the most common causes of traumatic brain injury include factors like traffic accidents (20\%), hit a barrier (19\%) and assault (11\%) (1). Traumatic brain injury can be classified into two types, primary and secondary. The primary injury occurs at the time of the accident causing direct damage to nerve tissue. Secondary damage is not seen at an early stage. Such harm is the natural and physiological response to the initial injury. Tissue hypoxia, which occurs within hours to months after the initial injury is this group (1). Early determination of prognosis after traumatic brain injury is a priority for relatives and physicians involved in the care of these patients $(2,3)$. New prognostic information beyond the clinical examination, patient demographics and radiological imaging from admission is needed to allow early prediction of short, mid, and long term outcome of patients with moderate and severe traumatic brain injury $(1,2,3)$. One of the factors involved in secondary damage that may occur following head trauma is the changes in blood parameters and biomarkers. Assessment of brain damage using biochemical tests and cerebrospinal fluid (CSF) and serum enzymes during the past decade has been done (4). Biomarkers of structural damage such as S-100, tau, enolase Neuron Specific (NSE) and myelin basic protein (MBP) may be used as potential diagnostic tools, prognostic and therapeutic supplements (1). The purpose of this study was to systematically review articles that studied the changes in hematological parameters in patients with traumatic brain injury and its correlation with the final outcome of treatment.of brain damage using biochemical tests, and cerebrospinal fluid (CSF) and serum enzymes during the past decade has been done (4). Biomarkers 
of structural damage, such as S-100, tau, enolase Neuron Specific (NSE) and myelin basic protein (MBP), may be used as potential diagnostic tools, prognostic and therapeutic supplements (1). The purpose of this study was to systematically review articles that studied the changes in hematological parameters in patients with traumatic brain injury and its correlation with the final outcome of treatment.

\section{Methods and Materials/Patients \\ Search strategy}

Sampling based on the search of information resources PUBMED, COCHRANE, Embase, Google scholar. Databases were searched for relevant publications between 2005 and 2014. The following keywords were used: prognosis, prognostic model, predict, head trauma, brain trauma, head injury, brain injury, biochemistric tests, biomarkers, blood markers, blood glucose, and serum markers.

\section{Study selection}

Two reviewers (FS and AM or AR) independently reviewed all publications and selected eligible studies. A third author (GS) was consulted in case of disagreement. We included cohort studies and determined serum factors concentrations in patients with moderate and/or severe traumatic brain injury as defined by a Glasgow coma score $<13$.

\section{Inclusion criteria were:}

1. (Due to the dramatic change in measuring biomarker concentrations and the treatment of traumatic injuries in recent years), studies which were published from 2005 until 2014.

2 . Studies in which, factors affecting the outcome after TBI were evaluated.

3. Studies that defined TBI as "acute changes in brain function resulting in a strong external force to the head.

4. Studies in which the result was measured by Glasgow Outcome Score or a comparable measure describing the activity limitation and neurological state.

5. Studies in which correlation between the measured factors in the first month after injury and the prognosis was addressed.

6 . The studies population were patients with moderate and/or severe $(\mathrm{GCS}<13)$ TBI with or without patients with mild injury or a subgroup consisting of patients with moderate or severe TBI were analyzed separately.

7. The article was written in English or English form of it was available.

\section{Quality Assessment}

Each paper was qualitatively evaluated according to criteria intended to establish study strength. These included:

1. Twenty-five or more patients in the series with complete followup.

2. Outcomes measured -Glasgow Outcome Scale or Mortality- at six months or more.

3.Data gathered prospectively, although retrospective examination from a database creating an ongoing cohort of patients could be used.

4.Glasgow Coma Scale score measured within 24 hours.

5.Appropriate statistics (e.g. multivariate analysis) was used to include adjustment for prognostic variables.

\section{Data Extraction}

Two reviewers (FS and AM or AR) independently collected data using a standardised data abstraction form. We abstracted information related to study design, patient characteristics, treatments (operative and pharmacological), laboratory aspects of the testing factor (type of assay used, time period of sampling, and sampling type) and clinical outcomes (outcome type and timing of assessment). In instances of duplicate reporting, we used data from the study that included the largest number of patients or, when available, individual patient data from each study. We contacted authors for clarification on study sample or for missing data. If multiple measurements were carried out, we used the first measurement after the injury for analysis. If outcomes were assessed at multiple time points, we used the measurement furthest from injury for analysis. Data of studies, inclusion and exclusion criteria, number of participants, time after injury, failure to continue follow-up, measurements of outcome, prognostic factors and results of their relationships with outcome were extracted using a standardized form.

\section{Analysis}

Significant relative risk ratios (RR), odds ratios (OR) or significant correlations $(\mathrm{P}<0.05)$ which were introduced by studies, was used to determine levels of evidence. If multivariate analysis was performed in the study, the results of it were used to establish the level of evidence. Otherwise, the results of the univariate analysis were used (table 1).

\section{Results}

\section{Study selection}

In total, 1021 citations were identified and after elimination of duplicates and screening and after using the inclusion and exclusion criteria, agreement was initially reached in 82 of articles and consensus was sought and finally, 63 articles were selected.

\section{Study characteristics}

The study characteristics are presented in Table 2. All articles were written in English. The number of patients studied was from 20 to 834 individuals with moderate to severe and sometimes mild traumatic brain injury. Penetrating trauma was not mentioned.

The main measure used for prognosis was GOS (30 studies). Other measures include mortality, GCS, ASI, PCPC, GOSE, EDSS, and DRS (Table 2). Most of the investigated factors were: blood glucose, serum protein S100 and NSE, as follows:16 study assessed the serum S100 protein (13 studied: S100B, 2 study: S100BB, 1 study: S100A1B), 22 study assessed the blood glucose levels and in 14 study, NSE levels were examined. 45 studies exclusively evaluated adults and 16 studies exclusively evaluated children. In other studies, age was not an entry criterion. Of all studies, in 20 studies, venous blood samples were taken. In 11 studies, arterial blood and in one study capillary blood (finger) was sampled. Other studies did not specify the sampling site.

\section{Neuronal markers:}

\section{Protein S100:}

According to the studies, serum concentration of S100 protein is a strong prognostic factor in adults and in children and there was strong evidence of relationship between serum levels of protein S100 and outcome. 19 studies were reviewed which assessed S100 protein in the blood as a prognostic factor in TBI. In all but two studies $(6,7)$, high levels associated with poor prognosis. All of these studies assessed serum levels of S100B but a study conducted in 2012 by Yousefzadeh et al. (28) evaluated the S100BB levels and Nyle'n et al. (62) studied serum levels of 3 types of this protein (S100B, S100A1B and S100BB). In studies on children with TBI $(6,9,10,11,12,13)$ in many of them significant 
correlation with the prognosis of patients was achieved except a study performed by Beers et al. (2007) (6) in which a statistical correlation between serum protein and GOS at 3-4 and 6-8 months after trauma was not found. Of the studies on the adults with traumatic brain injury $(7,8,15,16,17,18,19,20)$ all except one study (7) showed significant correlation between prognosis and S100 levels in serum.

\section{Neuron specific enolase:}

The evidence for the predictive value of concentration of neuron specific enolase in adults and in children with TBI was strong. 12 studies which had evaluated NSE as a prognostic factor were reviewed; all but three studies $(6,13)$ achieved significant associated between high levels of NSE and poor prognosis.

Six studies were performed on children with traumatic brain injury $(6,11,12)$ and seven studies on adults $(13,15,16,17,20,22,23)$

\section{Hyperphosphorylated neurofilament:}

According to the studies, serum concentration of NF-H is a strong prognostic factor in children. Two studies $(10,24)$ evaluated serum NF-H levels as a prognostic factor in TBI; Both studies performed on children in both studies, high levels associated with poor prognosis.

\section{Ubiquitin C-Terminal Hydrolase:}

5 articles that studied (Table 2) serum levels of UCHL1 as a prognostic factor in TBI were reviewed. All of them studied the correlation between UCHL1 values and GOS except for a study conducted in 2012 by L.Papa et al. (25) in which outcome measures included the following:

(1) GCS scores obtained at presentation to the ED,

(2) the presence of intracranial lesions on initial CT scan; and

(3) the need for neurosurgical intervention (NSI).

In this study, there was a significant relationship between all these three outcome measures, and levels of UCHL1 in adult patients with TBI. All of the other studies also found a significant correlation between high serum UCHL1 values and low GOS (unfavorable outcome).

\section{TAU Protein}

The evidence for the prognostic value of serum levels of TAU protein was Limited. Only one study (26) assessed serum levels of TAU protein as a prognostic factor in TBI. This study was conducted in 2008 by L. Nyle'n et al. (62) and reported high level of TAU protein levels as an independent risk factor for a poor outcome (GOS 1-3) ( $\mathrm{P}=0.043)$. ROC evaluating the ability of serum $\mathrm{t}$ protein level to predict a poor outcome showed an area under the curve of 0.939 with $88 \%$ sensitivity and $94 \%$ specificity at a serum TAU protein level of $114.5 \mathrm{pg} / \mathrm{mL}$.

\section{Myelin basic protein}

2 studies $(6,11)$ evaluated the levels of myelin basic protein (MBP) in serum, as a TBI prognostic factor. In the study which was performed on children under 15 years of age with traumatic brain injury, a significant relation was found between levels of this protein and the GOS, 3-4 and 6-8 months after trauma (6). In another study on children under 3 years who suffered a traumatic brain injury of varying intensities, high serum levels of MBP correlated with bad 6-month outcome which was measured by (Glasgow Outcome Scale using (GOS), Vineland Adaptive Behavior Scale (VABS) and the Intelligence Coefficient (IQ)

\section{Glial Fibrillary Acidic Protein}

The evidence for the prognostic value of serum levels of GFAP was strong. Seven studies $(7,10,27,28,29,30,31)$ investigated serum GFAP levels as a prognostic factor and all of them reported the high values of GFAP correlates with poor prognosis. Four studies evaluated prognosis of TBI in children and reminding were performed on adults. In a study performed by S. Mondello and coworkers (27) in 2011, multivariate logistic regression analysis showed that of all the variables assessed, only UCH-L1 was an independent predictor of mortality at discharge and also strongly predicted deaths in 6 months after the damage predicted. Highly significant correlation between UCH-L1 and GFAP were found. GFAP did not have an additional contribution when UCH-L1 was already entered in the model. Similar predictive value for GFAP and UCH-L1 $(\mathrm{c}=0.93)$ was determined.

\section{- Biochemical test}

\section{Blood sugar:}

In 22 studies, blood glucose levels were investigated as a prognostic factor. All but three studies $(32,33,34)$ reported that high levels of BS is associated with poor prognosis. All of the studies performed on children with traumatic brain injury $(35,36,37,38)$ achieved significant correlation between BS levels and patient prognosis. All of the studies on adults with traumatic brain injury $(32,33,3$ $4,40,41,42,43,44,45,46,47,48,49,50,74)$ and studies without a age limit $(51,52)$ reported a significant relationship between blood glucose levels and prognosis achieved except two studies $(32,34)$. The evidence for the prognostic value of BS levels was strong both in adults and in children with traumatic brain injury.

\section{Lactate Dehydrogenase:}

One study (53) evaluated Lactate Dehydrogenase levels as a prognostic factor of TBI. In both studies high levels were associated with poor prognosis. The evidence for the prognostic value of serum levels of LDH was strong. In V. Jain et al. study (68) in 2010, a significant relationship between serum LDH outcome after traumatic brain injury was found in patients with isolated brain trauma. In this study, the average increase in serum LDH was found in patients with a poor outcome and LDH levels increased continuously during the study period in both disabled and dead groups.

\section{Plasma Osmolarity:}

Two studies $(34,46)$ investigated plasma osmolarity as a prognostic factor. In a study by WhaSook Seo and HyunSoo Oh in 2009 (72) on patients with traumatic brain injury (and hemorrhagic stroke), 6 months after the trauma one of the physiologically significant predictors of cognitive abilities in patients with TBI was admission serum osmolarity $(\mathrm{p}=0.01)$, but there was no significant association between plasma osmolarity mortality and functional disability. In Nelson DW et al. study (49), poorer outcomes were observed with increasing osmolarity. According to these two studies, the evidence for the prognostic value plasma osmolarity was inconclusive.

\section{Total cholesterol:}

In WhaSook Seo and HyunSoo Oh study (72), 6 months after trauma, relationship between total cholesterol and mortality, cognitive abilities and functional disability in patients with TBI were not significant. In another study by Adel Helmy et al. (50), Total cholesterol only had a statistical relationship with traumatic brain injury outcome, via at least one other variable and was designated as 'level 2' of the hierarchy. According to these studies, serum total cholesterol probably is not a prognostic factor 
in patients with traumatic brain injury with a moderate level of evidence.

\section{Albumin:}

3 studies $(34,46,50)$ investigated albumin level as a prognostic factor in TBI. In WhaSook Seo and HyunSoo Oh study (72) and in Adel Helmy et al. study (50), correlation of albumin levels with outcome was like total cholesterol level. In Nelson DW et al. study (49), low albumin relationship with poor outcome in patients with TBI was statistically significant. According to these studies, the evidence for the prognostic value of low albumin was also inconclusive.

\section{Other biochemical tests:}

Nelson DW study in 2005 (61) reported blood creatinine as an independent predictor of outcome after TBI. In study by Helmy et al. (50), low magnesium only had a statistical relationship with outcome via at least two other variables and was designated as 'level 3' of the hierarchy. Hohl and colleagues in a study in 2012 (12) found that sodium in the blood of those who died after TBI was significantly higher. According to the above studies, the levels blood sodium was a strong prognostic factor of poor outcome in patients with traumatic brain injury, but the evidence for the prognostic value of the other variables was limited and uncertain.

\section{Complete Blood Count (CBC):}

\section{Hemoglobin}

Five studies $(34,43,46,48,50)$ were reviewed which assessed $\mathrm{Hb}$ levels as a prognostic factor in TBI. In 3 of them $(43,48,50)$, low levels associated with poor prognosis. In two studies $(34,46)$ there was no significant correlations between $\mathrm{Hb}$ levels and prognosis. According to the studies, there was inconclusive evidence of relationship between $\mathrm{Hb}$ level and outcome in traumatic brain injury.

\section{The leukocyte count}

Three studies $(38,50,55)$ were reviewed which assessed WBC count as a prognostic factor in TBI. None of them showed significant correlations between WBC levels and TBI prognosis. According to the studies, there was strong evidence of no relationship between WBC level and outcome in traumatic brain injury.

\section{- Blood Gases and ABG Results:}

3 studies $(34,39,43)$ were reviewed which assessed ABG results as a prognostic factor in TBI. In study by WhaSook Seo \& HyunSoo Oh (72), 6 months after trauma physiological predictors of mortality in patients with traumatic brain injury was arterial oxygen pressure $(\mathrm{F}=11.83, \mathrm{p}=0.00)$ and arterial carbon dioxide pressure $(\mathrm{F}=4.40, \mathrm{p}=0.02)$. In another study performed by Tude Melo et al. in 2010 (38), low blood oxygen saturation found to be a prognostic factor for mortality $(\mathrm{OR})=1.67$. According to the studies, there was a limited evidence of relationship between $\mathrm{PaCO} 2, \mathrm{PaO} 2, \mathrm{aPH}, \mathrm{O} 2$ sat and outcome of traumatic brain injury.

\section{Coagulation Factors and Products:}

8 studies $(23,31,38,39,43,58,71)$ were reviewed which assessed coagulation factors and products as a prognostic factor in TBI:

5 studies $(23,38,39,43,58)$ assessed prothrombin time $(\mathrm{PT})$ as a prognostic factor in TBI and all of them found a significant correlation between increased PT and poor outcome and mortality. So the evidence about prognosis prediction of PT is strong.
3 studies $(23,38,58)$ assessed partial thromboplastin time (PTT) as a prognostic factor in TBI and two studies $(38,58)$ found a significant correlation between increased a PTT and poor outcome. So the evidence about prognosis prediction of PTT is strong.

3 studies $(23,38,58)$ assessed platelet count as a prognostic factor in TBI and two studies $(23,58)$ found a significant correlation between decreased platelet count and poor outcome. So the evidence about prognosis prediction of platelet count is strong.

2 studies $(23,14)$ assessed D.dimer levels in serum as a prognostic factor in TBI and none of them found a significant correlation between its levels and outcome. Therefore, the evidence about that there is no relation between prognosis and levels of D.dimer is strong.

Only one study assessed each serum FDP levels (23) and serum VWF factor levels (31) found a significant correlation between them and outcome. Thus, the evidence about prognosis prediction of both of these is limited.

\section{-Acute Phase Reactants:}

\section{Heat Shock Protein 70 (HSP 70).}

2 studies $(58,59)$ assessed HSP 70 levels in serum as a prognostic factor in TBI and both of them found a significant correlation between its levels and outcome. So the evidence about prognosis prediction of HSP70 is strong.

\section{Pentraxin-PTX3}

Only one study (54) investigated Pentraxin-PTX3 serum protein as a prognostic factor. In this study which was conducted in 2011 by Jackson da Silva Gullo et al., (20) increased PTX3 levels correlated with mortality $(\mathrm{P}<0.04)$. Thus, the evidence about prognosis prediction of PTX3 levels is limited.

\section{-Inflammatory Factors:}

3 studies $(60,61,62)$ assessed some of the cytokines and inflammatory factors as prognostic factor in TBI. In Gopcevic et al. study (8), plasma level of IL-8 was significantly lower in survivors $(71.00+/-14.17 \mathrm{pg} / \mathrm{ml})$ than in non-survivors $(111.26$ $+/-16.9 \mathrm{pg} / \mathrm{ml}$ ). In Stein et al. study (60), median daily IL-8 levels associated with poor outcome, the median serum values of other Cytokine levels (IL-1B, IL-6, IL-8, IL-10, and TNF-alfa) were not different between 2 groups (GOSE 1-4 vs 5-8). In Soares et al. study (58), significant correlations of elevated serum levels of IL-10, but not TNF- $\alpha$, with hospital mortality in patients with severe TBI were reported $(p=0.01)$. Considering all these studies suggest that increased serum levels of IL-8 may be a strong prognostic factor but uncertain and limited predictive power of other inflammatory factors was seen.

\section{- Hormones \\ 1. ACTH \\ 2. Cortisol \\ 3. Estradiol \\ 4. Testosterone \\ 5. Progesterone \\ $6 . \mathrm{LH} \& \mathrm{FSH}$}

2 studies $(63,64)$ were reviewed which assessed Cortisol $(63,64)$, ACTH (63) and sex hormones (64) as prognostic factors in TBI. In K. Wagner et al. study (42), high estradiol and testosterone associated with mortality ( $\mathrm{p}=0.026$ and $\mathrm{p}=0.033$, respectively). Significant effect of LH, FSH, progesterone on mortality through their association with estradiol $(p=0.049)$. High estradiol was 
associated with worse outcomes. Stradiol mediated progesterone associations with GOS $(p=0.045)$. Serum cortisol was not associated with mortality or GOS. In Llompart-Poue et al. study (37), patients with low ACTH values $(<9 \mathrm{pg} / \mathrm{mL})$ : statistically significant lower mortality $(7 \%$ vs. $55 \%, \mathrm{p}<0.0001)$ and low plasma ACTH in patient who survived, correlated with increased ICU length of stay $(\mathrm{p}<0.03)$. But no significant differences with baseline and stimulated serum cortisol after a high-dose corticotrophin stimulation test were seen. According to these studies, the serum cortisol strongly has no relation with outcome of patients with brain injury. And the evidence of the prognostic value of serum levels other hormones mentioned, was inclusive.

\section{Matrix metalloproteinase 9:}

In the study conducted by M. DeFazio et al. (17) a significant difference in the mean concentration of MMP-9 at admission $(\mathrm{P}=0.115)$ or in $24 \mathrm{~h}(\mathrm{P}=0.535)$ was not found between the short term outcome groups. The study conducted by J. Copin et al. (11) a significant relationship between serum MMP-9 levels and three-month GOSE in patients with severe TBI was not seen. According to these studies, the serum MMP9 levels have no relation with outcome of patients with brain injury with moderate evidence.

\section{a II-Spectrin Breakdown Product 145kDa:}

Only one study (6) investigated serum SBDP145 level as a prognostic factor in TBI.

In one study (6), unfavorable outcome was correlated with higher concentrations of SBDP145.

According to this study, the evidence for the prognostic value of low SBDP145 was limited.

\section{Circulating endothelial progenitor cells:}

2 studies $(66,67)$ were reviewed which assessed circulating endothelial progenitor cells as prognostic factor in TBI.

In $\mathrm{Li}$ Liu et al. study (9), number of circulating EPCs was significantly lower in who died $\mathrm{p}<0.01$.

In Gong D et al. study (69), number of circulating EPCs was significantly correlated with GOS scores 6 months after TBI. Thus, the evidence for the predictive value of circulating endothelial progenitor cells was strong.

\section{- Miscellaneous:}

The studies of other factors, including serum oxidative stress parameters: thiobarbituric acid reactive species (TBARS) and carbonyl group (48), serum leptin (68) serum fibronectin CFn (65) and troponin cTnI were also reviewed which due to the low number of these studies for each factor, they can be a potential prognostic factors with limited evidence for TBI.

\section{Conclusion}

This systematic review summarized the results of 63 articles about the predictive value of various factors on prognosis after brain damage. Providing new information or explaining the findings in terms of pathophysiology is not the primary goal of a systematic review. Therefore, although relevant for clinicians, we were cautious not to speculate about underlying mechanisms or explanations for which no evidence was given in the included studies. Our study established strong evidence that serum concentration of S100 protein, neuron specific enolase, MBP, NFH, GFAP, UCH-L1, blood glucose levels, serum levels of LDH, sodium level, prothrombin time, partial thromboplastin time, platelet count, D.dimer, HSP 70, serum levels of IL-8, number of circulating EPCs, and DNA levels in serum were predictors of post-TBI outcome. This study found strong evidence that WBC count and serum cortisol levels do not predict outcome. Moreover, moderate evidence was found that serum total cholesterol count do not predict outcome. Moderate evidence showed that high serum MMP9 levels predict poor outcome. For all other determinants the evidence was limited or inconclusive. Although these profiles are best evidence for prognosis after TBI, they seem to be of limited value; hence still we are not able to correct or prevent or treat some of these factors. Overall, it can be concluded that much information is needed on long term outcome moderate and severe traumatic brain injury.

\section{Limitations of the review}

It was very difficult to reach a consensus on all epidemiological findings across the 63 published studies because of critical differences in methods employed across the reports. Firstly, we searched studies published between the 2005 and 2014. It is possible that relevant publications before or after that time were not included in this review. However, we think that it would be inappropriate to include older studies in a review on prognostic factors, because there have been dramatic changes in measuring biomarkers concentrations and the treatment of traumatic injuries over the last years.

Some of the included studies excluded penetrating head injury, other studies did not. Little information was given in the studies about how many patients had closed or open head injuries. It is not clear whether this has influenced our results. There was considerable heterogeneity for all outcomes of interest and in the time period over which outcome was evaluated. In the literature, different definitions for traumatic brain injury and the diagnostic methods are used. We decided to define brain injuries as the changes in brain function because of severe damage by an external force. We choose this fairly extensive definition is brain damage, so we would be able to enter many of the relevant studies. Furthermore, the populations studied were varied extensively in each literature from the other, in terms of gender, age, region and country in which they lived and were treated. Finally, we did not include studies published in languages other than English.

\section{Recommendations:}

Prediction of outcome after brain injury is not always straightforward, and there is always some uncertainty. Multiple factors may affect the outcome. Much of the literature available is written from an isolated neurological, neurosurgical or rehabilitation perspective. To improve outcome prediction, multidisciplinary research should take place, and knowledge should be integrated.

Although several biomarkers of brain injury have been identified, continued research is required. A single biomarker may not have desired sensitivity and specificity for predicting outcome. Biomarkers, in combination with other clinical data, such as GCS and head CT scan, would maximize the accuracy. Future studies will be required to not only identify these biomarkers prognostic ability together with other factors.

\section{Acknowledgment}

The authors would like to thank the staff of the Neurosurgery Ward of Imam-Hossein Hospital, Tehran, Iran.

\section{Funding}

None declared.

Conflicts of Interest

The authors declare that they have no competing interests. 
Table 1. Levels of evidence (6)

\begin{tabular}{|c|c|}
\hline Strong & Consistent findings $(\geq 80 \%)$ in at least 2 high quality cohorts \\
\hline Modrate & $\begin{array}{r}\text { One high-quality cohort and consistent findings } \\
(\geq 80 \%) \text { in one or more low-quality cohorts }\end{array}$ \\
\hline Limited & $\begin{array}{r}\text { Findings of one cohort or consistent findings } \\
(\geq 80 \%) \text { in one or more low-quality cohorts }\end{array}$ \\
\hline Inconclusive & Inconsistent findings irrespective of study quality \\
\hline
\end{tabular}

Table 2. Data Extraction in Prognosis Serum Factors in Traumatic Brain Injury

\begin{tabular}{|c|c|c|c|c|}
\hline Author(s) & Patient Characteristics & Outcome & Factor & Result \\
\hline $\begin{array}{l}\text { DeFazio et al. } \\
2013(5)\end{array}$ & $\begin{array}{l}\text { United states, ? patients, } 44 \text { completing. Age } \\
\text { 16-64 years. Inclusion: head injury, severe TBI GCS } \leq 8 \text {. admitted } \\
\text { within } 3 \text { hours of injury }\end{array}$ & $\begin{array}{l}\text { GCS } 72 \mathrm{~h}, \\
\text { mortality }\end{array}$ & $\begin{array}{l}\text { S100b,MMP-9, } \\
\text { D-dimer } 1^{\wedge} 24 \mathrm{~h} \\
\text { Venous blood samples } \\
\end{array}$ & $\begin{array}{l}\text { Significant: correlations: serum S-100B } 1^{\wedge} \text {. } \\
\text { plasma D-dimer, serum S-100B } 24 \mathrm{~h}\end{array}$ \\
\hline Lin et al. 2012 (31) & $\begin{array}{l}\text { China ? patiens, } 142 \text { completing,age below } 15 \text { years. Inclusion: } \\
\text { head injury, severe TBI GCS } \leq 8 \text {. admitted within } 6 \text { hours of } \\
\text { injury. Exclusion: disagreement of parents, recent infection, } \\
\text { previous TBI or history of seizure }\end{array}$ & $\begin{array}{l}\text { GOS } 1-3 \\
\text { vs } 4-5\end{array}$ & plasma leptin level & Significant \\
\hline $\begin{array}{l}\text { Chabok et al. } \\
2012(28)\end{array}$ & $\begin{array}{l}\text { Iran, } 414 \text { patients, } 28 \text { patients completing. Age }=>16 \text { years. } \\
\text { Inclusion: head trauma (GCS } \leq 8) \text {, without hematoma in CT and } \\
\text { any injury or with minor injuries such as lacerations in other } \\
\text { anatomic regions. admitted within } 3 \text { hours after injury. } \\
\text { Exclusion: acute alcohol intoxication, polytrauma, preexisting } \\
\text { disease, focal lesion in their second CT scan at } 48 \text { hours, who } \\
\text { died or were discharged before } 72 \text { hours of injury }\end{array}$ & $\begin{array}{l}\text { GOS } 1-3 \\
\text { vs } 4-5\end{array}$ & $\begin{array}{l}\text { NSE and S100BB } \\
6 \mathrm{~h} 24 \mathrm{~h} 48 \mathrm{~h} 72 \mathrm{~h} \\
\text { Venous blood samples }\end{array}$ & $\begin{array}{l}\text { not significant : NSE } 6 \mathrm{~h}, 24 \mathrm{~h} 48 \mathrm{~h} \\
\text { S100BB6 h } \\
\text { Significant :S100BB t } 24,48 \mathrm{~h} 72 \mathrm{~h} \text {. NSE72 } \\
\text { h }\end{array}$ \\
\hline $\begin{array}{l}\text { Papa et al. } \\
2012 \text { (34) }\end{array}$ & $\begin{array}{l}\text { United states, ? patients, } 96 \text { completing. Age } 18-89 \text { years. } \\
\text { Inclusion: adult patients with blunt head trauma followed by } \\
\text { either loss of consciousness, amnesia or disorientation and } \\
\text { present within } 4 \text { hours of injury with a GCS score of } 9-15 \text {. } \\
\text { Exclusion: age }<18 \text { years; no history of trauma, dementia, chronic } \\
\text { psychosis, active CNS pathology, pregnant or incarcerated }\end{array}$ & $\begin{array}{l}\text { GCS13-15 vs } \\
9-12 \\
\text { CT positive } \\
\text { vs negative }\end{array}$ & UCH-L1 & $\begin{array}{l}\text { Significant for both } \\
(p<0.001)\end{array}$ \\
\hline $\begin{array}{l}\text { Czeiter et al. } \\
2012(22)\end{array}$ & $\begin{array}{l}\text { Hungary, ? patients, } 45 \text { completing. Age }<18 \text { years years. } \\
\text { Inclusion: GCS score } \geq 8 \text { on admission caused by TBI less than } 24 \\
\text { h. Exclusion: age }<18 \text { years, autoimmune disease and pregnancy }\end{array}$ & $\begin{array}{l}\text { GOS } 1 \\
\text { vs } 2-5 \\
6 \text { months }\end{array}$ & $\begin{array}{l}\text { UCH-L1 } \\
\text { GFAP } \\
1 \mathrm{~h}, 6 \mathrm{~h}\end{array}$ & $\begin{array}{l}\text { Significant: } \\
\text { correlations: } \\
\text { lethal outcome: significant for GFAP_1H, } \\
\text { UCH-L1_1H, GFAP_24H, UCHL1_ } \\
\text { 24H } \\
\text { unfavorable: significant AUCs for GFAP_1H, } \\
\text { UCH-L1_1H, } \\
\text { GFAP_24H, UCH-L1_24H }\end{array}$ \\
\hline $\begin{array}{l}\text { Gong et al. } \\
2012(69)\end{array}$ & $\begin{array}{l}\text { China. ? patiens, } 21 \text { completing, age }>16 \text { years. Inclusion: head } \\
\text { injury, severe TBI. GCS } \leq 8 \text {. admitted within } 6 \text { hours of injury }\end{array}$ & $\begin{array}{l}\text { GOS scores } 6 \\
\text { months }\end{array}$ & $\begin{array}{l}\text { endothelial progenitor } \\
\text { cells on days } 1,4,7, \\
14 \text { and }\end{array}$ & $\begin{array}{l}\text { Significant: } \\
\text { correlations;EPCs } 7 \text { days }\end{array}$ \\
\hline $\begin{array}{l}\text { Hohl et al. } \\
2012 \text { (17) }\end{array}$ & $\begin{array}{l}\text { Brazil, ?patiens, } 79 \text { completing, age } 18-80 \text { years. Inclusion: } \\
\text { with severe TBI admitted to the intensive care unit, GCS } 8 \text { or } \\
\text { lower after the ICU admission. Exclusion: Victims of gunshot } \\
\text { injury and patients who evolved to brain death before } 24 \text { hours } \\
\text { of admission }\end{array}$ & $\begin{array}{l}\text { Hospital } \\
\text { mortality }\end{array}$ & $\begin{array}{l}\text { Oxidative stress } \\
\text { parameters: } \\
\text { thiobarbituric acid } \\
\text { reactive species } \\
\text { (TBARS) carbonyl } \\
\text { groups } \\
\text { 1st, 2nd, and 3rd day } \\
\text { blood pH, glucose, } \\
\text { sodium, Hct, Hb } \\
\text { Venous blood samples } \\
\end{array}$ & $\begin{array}{l}\text { no statistical differences in plasma levels } \\
\text { of TBARS and protein carbonyl groups } \\
\text { between survivors and non-survivors who } \\
\text { died had significantly higher } \mathrm{pH}(\mathrm{P}=.01) \\
\text { glucose }(\mathrm{P}=.04) \text { and } \mathrm{Na} \& \text { lower levels of } \\
\text { Hct and } \mathrm{Hb}\end{array}$ \\
\hline $\begin{array}{l}\text { Zurek et al. } \\
2012(64)\end{array}$ & $\begin{array}{l}\text { United states, ? patients, } 49 \text { completing. Age } 8-204 \text { months. } \\
\text { Inclusion: head injury. admitted within } 3 \text { hours of injury }\end{array}$ & $\begin{array}{l}\text { GOS } \\
1 \text { vs } 2-5\end{array}$ & $\begin{array}{l}\text { Serum pNF-H } \\
\text { Venous blood samples } \\
\text { admission and every } \\
24 \text { h for } 6 \text { days }\end{array}$ & $\begin{array}{l}\text { The quantitative level of } \mathrm{pNF}-\mathrm{H} \text { remained } \\
\text { significantly higher in GOS=1 }\end{array}$ \\
\hline $\begin{array}{l}\text { Mondello et al. } \\
2012(56)\end{array}$ & $\begin{array}{l}\text { United states, ? patients, } 95 \text { completing. Age }<18 \text { years. } \\
\text { Inclusion: TBI patients GCS of } 8 \text { and a ventricular intracranial } \\
\text { pressure monitoring as part of their routine clinical care. Patients } \\
\text { with multiple trauma were excluded (Injury Severity Score=15) }\end{array}$ & $\begin{array}{l}\text { survival in first } \\
7 \text {-day } \\
\text { GOS }=1 \\
\text { vs } 2-5 \\
3 \text { months }\end{array}$ & $\begin{array}{l}\text { blood UCH-L1 } \\
\text { every } 6 \text { hours up to a } \\
\text { maximum of } 7 \text { days }\end{array}$ & $\begin{array}{l}\text { Significant: } \\
\text { correlations: } \\
7 \text { day mortality: }(\mathrm{P}=.01) \\
3 \text { months mortality }\end{array}$ \\
\hline
\end{tabular}




\begin{tabular}{|c|c|c|c|c|}
\hline Author(s) & Patient Characteristics & Outcome & Factor & Result \\
\hline $\begin{array}{l}\text { Copin et al. } \\
2012(11)\end{array}$ & $\begin{array}{l}\text { Switzerland. ? patients, } 49 \text { completing, age } 25-55 \text { years. } \\
\text { Inclusion: Patients with TBI from blunt trauma were enrolled } \\
\text { and included if severe TBI was confirmed by cerebral CT scan }\end{array}$ & $\begin{array}{l}\text { 1. ICU LOS of } \\
\text { survivors } \\
\text { 2. Death before } \\
3 \mathrm{~m} \\
\text { 3. Consciousness } \\
\text { at } 14 \text { days } \\
\text { 4. GOSE at } 3 \\
\text { months } \\
\end{array}$ & $\begin{array}{l}\text { MMP-9, c-Fn } \\
\text { at } 6,12,24 \text { and } 48 \\
\text { hours }\end{array}$ & $\begin{array}{l}\text { Significant: } \\
\text { correlations; } \\
\text { 1. early MMP-9 }(+32 \%, \mathrm{p}=0.14, \mathrm{n}=34) \\
\text { or late c-Fn concentration }(+127 \%, \mathrm{p}= \\
0.06, \mathrm{n}=34)\end{array}$ \\
\hline $\begin{array}{l}\text { Soares et al. } \\
2012(58)\end{array}$ & $\begin{array}{l}\text { Brazil, ? patients, } 93 \text { patients completing, age }>16 \text { years old, } \\
\text { Inclusion: severe TBI (GCS } 3-8 \text { ) presented within } 24 \text { hours of } \\
\text { the head injury }\end{array}$ & $\begin{array}{l}\text { hospital } \\
\text { mortality }\end{array}$ & $\begin{array}{l}\text { serum levels of IL-10, } \\
\text { and } \\
\text { TNF- } \alpha \\
10 \mathrm{~h}, 30 \mathrm{~h}, 68 \mathrm{~h}\end{array}$ & $\begin{array}{l}\text { Significant: } \\
\text { correlations: } \\
\text { Elevated serum levels of IL-10, but not } \\
\text { TNF- } \alpha \text {, with hospital mortality }(\mathrm{p}=0.01)\end{array}$ \\
\hline $\begin{array}{l}\text { Macher et al. } \\
2012(25)\end{array}$ & $\begin{array}{l}\text { Spain, ? patients, } 65 \text { patients completing, age } 16<\text { years. } \\
\text { Inclusion: admitted at ICU suffering severe trauma brain } \\
\text { injury }(\mathrm{GCS}<9) \text {. Exclusion: previous history of neurological or } \\
\text { psychiatric disease }\end{array}$ & $\begin{array}{l}\text { survival/non- } \\
\text { survival }\end{array}$ & $\begin{array}{l}\text { Circulating cell-free } \\
\text { DNA levels } \\
\text { At study entry and } \\
\text { after } 24,48 \mathrm{~h}\end{array}$ & $\begin{array}{l}\text { Increased DNA levels: } \\
\text { correlations: non-survival }\end{array}$ \\
\hline $\begin{array}{l}\text { Gopcevicet al. } \\
2012(8)\end{array}$ & $\begin{array}{l}\text { Croatia, ?patients, } 20 \text { patients completing. Age }>16 \text { years, } \\
\text { Inclusion: isolated severe TBI admitted to ICU, (GCS } \leq 8) \text {, } \\
\text { Exclusion: injury of other organs, dementia, acute infection, } \\
\text { stroke, using anti-Inflammatory drugs, autoimmune disease }\end{array}$ & survival rates & $\begin{array}{l}\text { Plasma interleukin-8 } \\
\text { blood samples from } \\
\text { central venous and } \\
\text { jugular bulb catheter at } \\
\text { admission }\end{array}$ & $\begin{array}{l}\text { Central venous plasma level of IL- } 8 \text { was } \\
\text { significantly lower in survivors }(71.00+/- \\
14.17 \mathrm{pg} / \mathrm{ml}) \text {, than in non-survivors } \\
(111.26+/-16.9 \mathrm{pg} / \mathrm{ml})\end{array}$ \\
\hline $\begin{array}{l}\text { Smith et al. } \\
2012(30)\end{array}$ & $\begin{array}{l}\text { United states, ? patients, } 57 \text { completing. Age 9-90 years. } \\
\text { Inclusion: Head trauma GCS } \leq 8\end{array}$ & $\begin{array}{l}\text { GOS } 1-2 \\
\text { vs } 3-5\end{array}$ & $\begin{array}{l}\text { hyperglycemia serum } \\
\text { Blood glucose }>11.1 \\
\mathrm{mmol} / 1(200 \mathrm{mg} / \mathrm{dl}) \\
\text { Early (first } 48 \mathrm{hrs}) \text { and } \\
\text { Late }(49-168 \mathrm{hrs}) \\
\text { arterial blood samples }\end{array}$ & $\begin{array}{l}\text { Significant: In the Late period, an } \\
\text { association between elevated mean serum } \\
\mathrm{BS} \text { and outcome was observed }(133.5+-5.6 \\
\mathrm{mg} / \mathrm{dL} \text { in unfavorable group vs. } 115.4+-4.1 \\
\mathrm{mg} / \mathrm{dL} \text { in favorable group, } \\
\mathrm{p}=.02) \text {. }\end{array}$ \\
\hline $\begin{array}{l}\text { Goyal et al. } \\
2012(1)\end{array}$ & $\begin{array}{l}\text { United states, ? patients, } 80 \text { completing. Age }>16 \text { years. Inclusion: } \\
\text { adult subjects with severe TBI. Exclusion: Brain injury due to } \\
\text { other causes; associated with other tissue injury, liver disorders, } \\
\text { renal diseases, hyperuricemias }\end{array}$ & \begin{tabular}{|l|} 
acute mortality \\
GOS \\
Disability Rating \\
Scale (DRS) \\
\end{tabular} & $\begin{array}{l}\text { S100b in serum within } \\
24 \text { hours }\end{array}$ & $\begin{array}{l}\text { higher } \mathrm{S} 100 \mathrm{~b} \text { concentrations had higher } \\
\text { acute mortality }(\mathrm{p}<0.001) \text { and with worse } \\
\text { GOS scores }(\mathrm{p}=0.002) \text { and Disability } \\
\text { Rating Scale (DRS) scores }(\mathrm{p}=0.039) 6 \\
\text { months post-injury. }\end{array}$ \\
\hline $\begin{array}{l}\text { Olivercrona } \\
\text { et al. } 2012(64)\end{array}$ & $\begin{array}{l}\text { Sweden, ? patiens, } 21 \text { completing, Inclusion: verified head injury, } \\
\text { GCS } \leq 8 \text {, age } 15-70 \text { years, an initial } \mathrm{CPP} \geq 10 \mathrm{mmHg} \text {. Arrived } \\
\text { within } 24 \text { hours. Exclusion: penetrating head injuries, pregnant } \\
\text { or breastfeeding women. initial } \mathrm{CPP}<10 \mathrm{mmHg} \text { were regarded } \\
\text { as dead on arrival }\end{array}$ & \begin{tabular}{|l|} 
GOS \\
3 and 12 months \\
$1-3$ \\
vs $4-5$ \\
1 \\
vs $4-5$ \\
\end{tabular} & $\begin{array}{l}\text { S-100B and NSE was } \\
\text { sampled twice daily } \\
\text { during the first five } \\
\text { days }\end{array}$ & $\begin{array}{l}\text { S-100B\& NSE higher GOS } 1 \text { at } 3 \text { and } 12 \\
\text { months compared with GOS } 2-5(\mathrm{p}<0.01) \text {. } \\
\text { Nostatistically significant difference } \\
\text { in S-100B\& NSE when results were } \\
\text { dichotomized into unfavourable (GOS 1-3) } \\
\text { and favourable (GOS 4-5) outcome. } \\
\end{array}$ \\
\hline $\begin{array}{l}\text { Saadat et al. } 2012 \\
(44)\end{array}$ & $\begin{array}{l}\text { Iran , } 122 \text { patiens, } 116 \text { completing, all children and adolescents } \\
\text { admitted to the emergency room and ICU with blunt trauma with } \\
\text { severe traumatic brain injury }(\mathrm{GCS} \leq 8) \text {, who were younger than } \\
18 \text { years of age, admitted to the emergency room within the first } \\
12 \text { hours of injury. Exclusion: died within } 48 \text { h of admission or } \\
\text { had a history of diabetes mellitus }\end{array}$ & $\begin{array}{l}\text { mortality rate, } \\
\text { hospital length } \\
\text { of stay (LOS) }\end{array}$ & $\begin{array}{l}\text { Admission and daily } \\
\text { BS, up to the end } \\
\text { of the third day of } \\
\text { ICU peripheral vein } \\
\text { samples }\end{array}$ & $\begin{array}{l}\text { Persistent high BS in first } 2 \text { and } 3 \text { days: } \\
5, \quad 10 \text {-fold increased risk of mortality, } \\
\text { respectively }(\mathrm{P}<0.001 \text { for both) } \\
\text { BS of survivals not correlated with LOS } \\
\text { in, whereas BS of who died :inversely } \\
\text { correlated with LOS in days } 1 \text { and } 2 \\
(\mathrm{P}=0.014 \text { and } \mathrm{P}=0.039 \text {, respectively). }\end{array}$ \\
\hline $\begin{array}{l}\text { Priscoet al. } \\
2012(73)\end{array}$ & $\begin{array}{l}\text { United states, ? patients, } 39 \text { completing. Age }<15 \text { years. Inclusion: } \\
\text { had a head CT, had blood collected for biomarker measurement } \\
\text { within } 24 \text { hours }\end{array}$ & $\begin{array}{l}\text { GOS score } \\
(1=\text { good } \\
\text { outcome, } \\
5=\text { death }) \\
3-4 \text { months } 6-8 \\
\text { months }\end{array}$ & $\begin{array}{l}\text { UCH-L1, } \\
\text { SBDP145,NSE, } \\
\text { S100B, MBP }\end{array}$ & $\begin{array}{l}\text { Significant: } \\
\text { correlations: } \\
\text { unfavorable: Higher concentrations of both } \\
\text { UCH-L1 and SBDP } \\
\text { no correlation between NSE, S100B, or } \\
\text { MBP and outcome. }\end{array}$ \\
\hline $\begin{array}{l}\text { Matsushima et al. } \\
2012(40)\end{array}$ & $\begin{array}{l}\text { United states, } 282 \text { patients, } 109 \text { completing. Age } 23-55 \text { years; } \\
\text { Inclusion: Abbreviated Injury } \\
\text { Scale of head of } 3 \text { to } 5 \text {, SICU length of stay }>2 \text { days) TGC } \\
\text { protocol instituted during the entire ICU stay. } \\
\text { Exclusion: age } \leq 13 \text { years, brain tumor, previous brain injury, } \\
\text { encephalitis/meningitis, brain abscess, vascular malformation, } \\
\text { MS, Alzheimer, HIV, encephalitis, or stroke; difficult F/U } \\
\text { including homeless or incarcerated patients; mortality during the } \\
\text { initial hospital stay }\end{array}$ & GOS 6 months & $\begin{array}{l}\text { Hourly } \\
\text { glucose level was } \\
\text { measured using } \\
\text { finger capillary blood } \\
\text { sampling }\end{array}$ & $\begin{array}{l}\text { Higher mean glucose levels (OR: } 1.28 \text { for } \\
\text { a } 10-\mathrm{mg} / \mathrm{dL} \text { increase; } \mathrm{P}=.05 \text { ): significantly } \\
\text { associated with lower GOSE score. (Mean } \\
\text { glucose of } 130 \mathrm{mg} / \mathrm{dL} \text { has } 1.28 \text { times higher } \\
\text { odds of a lower GOSE score compared with } \\
\text { mean glucose } 120 \mathrm{mg} / \mathrm{dL} \text {. }\end{array}$ \\
\hline $\begin{array}{l}\text { Liu et al. } \\
2011 \text { (9) }\end{array}$ & $\begin{array}{l}\text { China, ?patients, } 84 \text { completing. Age: } 18-85 \text { years. Inclusion: } \\
\text { head injury, TBI, } \\
\text { Exclusion criteria include patients with complex trauma in trunk } \\
\text { and limbs, hematologic disorders, cancer and patients on sedation }\end{array}$ & $\begin{array}{l}\text { deteriorated } \\
\text { or improved } \\
\text { outcomes (GCS) } \\
\text { mortality }\end{array}$ & $\begin{array}{l}\text { EPC, BS } \\
\text { Morning fasting } \\
\text { venous blood } 1,4,7 \\
14, \text { and } 21 \text { days }\end{array}$ & $\begin{array}{l}\text { number of circulating } \\
\text { EPCs was significantly lower in who died } \\
\mathrm{p}<0.01 \text {. BS was significantly higher in who } \\
\text { died or deteriorated }\end{array}$ \\
\hline
\end{tabular}




\begin{tabular}{|c|c|c|c|c|}
\hline Author(s) & Patient Characteristics & Outcome & Factor & Result \\
\hline $\begin{array}{l}\text { Maaty et al. } \\
2011 \text { (28) }\end{array}$ & $\begin{array}{l}\text { Egypt, ? patients, } 100 \text { completing. Age: } 22-71 \text { years. } \\
\text { Inclusion:all patients who had sustained TBI either alone or as } \\
\text { a part of multiple trauma. Exclusion: brain death, penetrating } \\
\text { injury, infection and possible diseases that alter the parameters. }\end{array}$ & Mortality & $\begin{array}{l}\text { serum S100 protein } \\
\text { NSE, GFAP } \\
\text { venous blood samples }\end{array}$ & $\begin{array}{l}\text { Significant: correlations: } \\
\text { Non-survivors higher admission serum } \\
\text { S100 protein and GFAP levels;serum } \\
\text { NSE was non-significantly higher in non- } \\
\text { survivors }\end{array}$ \\
\hline $\begin{array}{l}\text { Salehpour et al. } \\
2011(59)\end{array}$ & $\begin{array}{l}\text { Iran, ? patients, } 52 \text { completig. Age }>18 \text { inclusin: } 52 \text { patients with } \\
\text { severe head trauma }(G C S, \leq 8) \text {. Patients with major accompanying } \\
\text { trauma were excluded. }\end{array}$ & $\begin{array}{l}\text { GOS } \\
\text { mortality } 6 \\
\text { months }\end{array}$ & $\begin{array}{l}\text { platelet count, PT, } \\
\text { PTT, INR }\end{array}$ & $\begin{array}{l}\text { Significant negative correlations were } \\
\text { found between PT, PTT, and INR with GOS } \\
\text { scores and mortality } \\
\text { Significant positive correlations were found } \\
\text { between the platelet count and GOS scores } \\
\text { and mortality }\end{array}$ \\
\hline $\begin{array}{l}\text { Žureket al. } 2011 \\
(64)\end{array}$ & $\begin{array}{l}\text { Czech Republic, ? patients, } 63 \text { pediatric patients completing, } \\
\text { age } 0 \text { - } 19 \text { years old,Inclusion: TBIs, maximum of } 12 \mathrm{~h} \text { before } \\
\text { admission. TBIs were verified by computerized tomography } \\
\text { (CT). Exclusion: whose parents (legal guardians) }\end{array}$ & $\begin{array}{l}\text { GOS } 1-3 \\
\text { vs } 4-5\end{array}$ & $\begin{array}{l}\text { NSE ,S100B,GFAP, } \\
\text { pNF-H, secretagogin } \\
\text { and Hsp70 } \\
\text { Average within } 6 \text { days } \\
\text { Venous blood }\end{array}$ & $\begin{array}{l}\text { Significant: correlations: unfavorable: } \\
\text { S100B, NSE and GFAP levels }(\mathrm{p}<0.001) \\
\text { not significant: pNF-H, secretagogin and } \\
\text { Hsp70 }\end{array}$ \\
\hline $\begin{array}{l}\text { Stein et al. } \\
2011(60)\end{array}$ & $\begin{array}{l}\text { United states, ? patients, } 24 \text { patients completing. Age18- } \\
83 \text { years.Inclusion: admission within the first } 6 \mathrm{~h}, \mathrm{GCS}<9, \\
\text { placement of a clinically indicated ICP monitor. TBI confirmed } \\
\text { by CT. Exclusion: multisystem trauma, nonsurvivable injury }\end{array}$ & $\begin{array}{l}\text { GOS } 1-4 \\
\text { vs } 5-8\end{array}$ & $\begin{array}{l}\text { Cytokine levels (IL- } \\
1 \mathrm{~B}, \mathrm{IL}-6, \mathrm{IL}-8, \mathrm{IL}-10, \\
\text { and TNF-alfa) } \\
\text { admission + twice } \\
\text { daily for7days } \\
\text { arterial blood samples } \\
\end{array}$ & $\begin{array}{l}\text { median daily IL- } 8 \text { levels: associated with } \\
\text { poor outcome, the median serum values of } \\
\text { others were not different between } 2 \text { groups }\end{array}$ \\
\hline $\begin{array}{l}\text { Fraser et al. } \\
2011(13)\end{array}$ & $\begin{array}{l}\text { United states, ? patients, } 24 \text { patients completing. Age18- } \\
83 \text { years. Inclusion: admission within the first } 6 \mathrm{~h} \text {, GCS }<9 \text {, } \\
\text { placement of a clinically indicated ICP monitor. TBI confirmed } \\
\text { by CT. Exclusion : multisystem trauma, nonsurvivable injury. } \\
\text { Canada,? patients, } 27 \text { pediatric patients completing, age } \\
1-17 y \text { years old, Inclusion: age } 1-17 \text { y, TBI GCS } \leq 8 \text {, CT scan } \\
\text { showing acute brain injury, need for mechanical ventilation. } \\
\text { Exclusion enrolled }>8 \text { hrspostinjury, refractory shock, suspected } \\
\text { brain death, intentional injury, prolonged cardiac arrest, high } \\
\text { cervical spinal cord injury, severe neurodevelopmental disability } \\
\text { before the injury, brain injury secondary to a gunshot wound, } \\
\text { acute isolated epidural hematoma, or pregnancy. }\end{array}$ & $\begin{array}{l}\text { PCPC } \\
\text { score at } 6 \\
\text { months }\end{array}$ & $\begin{array}{l}\text { GFAP daily } \\
\text { arterial blood samples }\end{array}$ & $\begin{array}{l}\text { Serum GFAP concentrations correlated with } \\
\text { PCPC } \\
\text { scores ( }<<.008 \text { ) } \\
\text { GFAP concentrations on PICU day } 1 \\
\text { associated with a good outcome (PCPC } \\
\text { score of }=<2 \\
\text { (normal to mild disability) }\end{array}$ \\
\hline $\begin{array}{l}\text { Mondello et al. } \\
2011 \text { (27) }\end{array}$ & $\begin{array}{l}\text { United states, ? patients, } 81 \text { completing. Age } \geq 18 \text { years; } \\
\text { Inclusion: GCS eight or less. Exclusion: younger than } 18 \text { years; } \\
\text { no history of trauma;known dementia, chronic psychosis, or } \\
\text { active CNS pathology; pregnant; incarcerated }\end{array}$ & $\begin{array}{l}\text { GOS } 1 \\
\text { vs } 2-5\end{array}$ & $\begin{array}{l}\text { UCH-L1 and GFAP } \\
\text { Venous blood samples } \\
\text { at admission } \\
\text { (median seven hours) } \\
\text { and every six hours } \\
\text { thereafter } \\
\end{array}$ & $\begin{array}{l}\text { UCH-L1 was the only independent predictor } \\
\text { of death at discharge [adjusted odds ratios } \\
2.95 \text {; ], but both UCH-L1 and GFAP levels } \\
\text { strongly predicted death } 6 \text { months post- } \\
\text { injury }\end{array}$ \\
\hline $\begin{array}{l}\text { Mc Gozales-Mao } \\
\text { et al. } 2011 \text { (57) }\end{array}$ & $\begin{array}{l}\text { Spain,? patients, } 149 \text { completing. Age } 15-84 \text { years. Inclusion: 1) } \\
\text { Arrival within } 6 \text { h of the injury. 2) Main diagnosis of TBI. 3) } \\
\text { Evaluation of a history of psychiatric and neurological disease. } \\
\text { 4) Completion of a CT scan within } 24 \text { h.Exclusion: Patients with } \\
\text { some circumstance related to elevated serum levels of S100B } \\
\text { such as Down's syndrome, Alzheimer's disease, schizophrenia, } \\
\text { bipolar disorder, multiple sclerosis, melanoma, glioblastoma }\end{array}$ & $\begin{array}{l}\text { GOS, } \\
\text { mortality }\end{array}$ & $\begin{array}{l}\text { S100B at } 6,24,48 \text { and } \\
72 \text { hours }\end{array}$ & $\begin{array}{l}\text { Significant: } \\
\text { correlations: between the GOS S100B : a } \\
\text { negative and significant correlation for all } \\
\text { the sampling times. } \\
\text { The average levels of S100B at } 6,24,48, \\
\text { and } 72 \mathrm{~h} \text { in all cases, significantly higher } \\
\text { in the exitus group compared with the } \\
\text { survivors }(\mathrm{p}<0.05)\end{array}$ \\
\hline $\begin{array}{l}\text { Greuters et al. } \\
2011(21)\end{array}$ & $\begin{array}{l}\text { Netherlands, } 247 \text { patients, } 107 \text { completing, age }>18 \text { years. } \\
\text { Inclusion: TBI, GCS of } 8 \text { or less who survived for } 5 \text { days or more. } \\
\text { Exclusion: medical record lacked complete data, or if the GCS } \\
\text { improved to } 13 \text { or higher over the initial } 24 \text { hours }\end{array}$ & $\begin{array}{l}\text { hospital } \\
\text { mortality }\end{array}$ & $\begin{array}{l}\text { APTT, INR,PT, platelet } \\
\text { count, } \\
\text { within } 72 \mathrm{~h} \\
\text { (Coagulopathy defined } \\
\text { as a PTT }>40 \text { seconds } \\
\text { and/or INR }>1.2 \text { and/ } \\
\text { or a platelet count } \\
<120 * 109 \text { per liter) } \\
\end{array}$ & $\begin{array}{l}\text { both coagulopathy upon ED arrival and } \\
\text { during the first } 24 \mathrm{~h} \text { : an independent } \\
\text { prognostic factor for unfavorable outcome } \\
(\mathrm{P}=0.04) \text { and }(\mathrm{P}=0.003)\end{array}$ \\
\hline $\begin{array}{l}\text { Aş1lioğlu et al. } \\
2011 \text { (2) }\end{array}$ & $\begin{array}{l}\text { Turkey, ? patients, } 65 \text { completing. Age }<18 \text { years. Inclusion: } \\
\text { under } 18 \text { years of age and were admitted to the PICU severe head } \\
\text { trauma, defined by an initial GCS }<8 \text {. None of these children } \\
\text { received intravenous infusion of glucose or steroid therapy and } \\
\text { none had a previous history of diabetes mellitus or endocrine } \\
\text { disease. Exclusion: patients without a documented blood glucose } \\
\text { value at the time of admission }\end{array}$ & $\begin{array}{l}\text { GOS at hospital } \\
\text { discharge and } 6 \\
\text { months }\end{array}$ & $\begin{array}{l}\text { levels of blood glucose } \\
\text { venous blood sample }\end{array}$ & $\begin{array}{l}\text { mean glucose level of the patients in bad } \\
\text { outcome group at hospital discharge and } 6 \\
\text { months was found to be significantly higher } \\
p=0.01, p=0.04 \text {, respectively }\end{array}$ \\
\hline
\end{tabular}




\begin{tabular}{|c|c|c|c|c|}
\hline Author(s) & Patient Characteristics & Outcome & Factor & Result \\
\hline $\begin{array}{l}\text { DeOliveiraet al. } \\
2011(70)\end{array}$ & $\begin{array}{l}\text { Brazil, ? patients, } 44 \text { patients completing, age } 18-64 \text { years old. } \\
\text { Inclusion: severe TBI (GCS } 3-8 \text { at emergency room admission), } \\
\text { without previous history of neurological or psychiatric disease, } \\
\text { transferred to the trauma ICU within } 24 \text { h of the head injury }\end{array}$ & $\begin{array}{l}\text { GOS 1-3 } \\
\text { vs } 4-5 \\
\text { at the ICU } \\
\text { discharge } \\
\text { survivors/non- } \\
\text { survivors } \\
\text { Venous blood } \\
\text { samples }\end{array}$ & $\begin{array}{l}\text { Plasma VWF } \\
\text { antigen (VWF:Ag) } \\
\text { levels at admission, } 24 \\
\text { h, } 7 \text { days } \\
\text { total serum protein } \\
\text { Venous blood samples }\end{array}$ & $\begin{array}{l}\text { Significant: } \\
\text { correlations: initial VWF, Ag: nonsurvivors } \\
(\mathrm{p}<0.001) \\
\text { not significant } \\
\text { 1.initial plasma VWF oncentrations and } \\
\text { outcome } \\
\text { 2.total serum protein between survivors } \\
\text { and } \\
\text { Non-survivors }\end{array}$ \\
\hline $\begin{array}{l}\text { Wagner A.K et al. } \\
2011(42)\end{array}$ & $\begin{array}{l}\text { United states,? patients, } 117 \text { completing. Age } 16-75 \text {. Inclusion: } \\
\text { severe TBI GCS } \leq 8 \text { with positive findings on head CT, required } \\
\text { an EVD, and had at least two serum samples available for } \\
\text { analysis. Exclusion: penetrating brain injury or prolonged } \\
\text { cardiac or respiratory arrest at injury previous history of pituitary } \\
\text { or hypothalamic tumor, history of breast cancer requiring } \\
\text { chemotherapy treatment/tamoxifen, history of prostate cancer } \\
\text { requiring orchiectomy or LH suppression agents, or untreated } \\
\text { thyroid disease }\end{array}$ & $\begin{array}{l}\text { GOS } 1 \text { vs. } 2 / 3 \\
\text { vs. } 4 / 5\end{array}$ & $\begin{array}{l}\text { Serum cortisol, } \\
\text { testosterone, } \\
\text { progesterone, and } \\
\text { estradiol at } \sim 7: 00 \text { a.m. } \\
\text { daily }\end{array}$ & $\begin{array}{l}\text { High estradiol and testosterone associated } \\
\text { with mortality ( } \mathrm{p}=0.02 \text { and } \mathrm{p}=0.03 \text {, } \\
\text { respectively), and GOS. } \\
\text { significant effect of LH } \\
\mathrm{FSH} \text { progesterone on mortality through } \\
\text { their association with estradiol ( } \mathrm{p}=0.04) \text {. } \\
\text { Estradiol mediated progesterone } \\
\text { associations with ( } \mathrm{p}=0.04) \text {. Serum cortisol } \\
\text { was not associated with mortality or GOS }\end{array}$ \\
\hline $\begin{array}{l}\text { Jain et al. } 2010 \\
(67)\end{array}$ & $\begin{array}{l}\text { India. ? patiens, } 63 \text { patients completing,age: no age exclusion. } \\
\text { Inclusion: Isolated head injury patients with no extracerebral } \\
\text { injury. Exclusion: Any patient revealing extracerebral injury, } \\
\text { either at admission or at subsequent follow-up }\end{array}$ & \begin{tabular}{|l|} 
Outcome \\
specified as (1) \\
dead (2) severely \\
disabled \\
(3) Moderately \\
disabled (4) \\
good \\
\end{tabular} & $\begin{array}{l}\text { Serum LDH at } \\
\text { admission and serially } \\
\text { on } 5 \text { days arterial blood } \\
\text { sample }\end{array}$ & $\begin{array}{l}\text { significantly: high mean serum LDH in } \\
\text { patients with poor outcome }\end{array}$ \\
\hline $\begin{array}{l}\text { Melo et al. } 2010 \\
\text { (51) }\end{array}$ & $\begin{array}{l}\text { France, } 315 \text { patients, } 286 \text { completing. Age } 1 \text { month to } 17 \text { years } \\
\text { Inclusion: severe TBI GCS } \leq 8\end{array}$ & $\begin{array}{l}\text { Mortality } \\
\& \\
\text { GOS } 2-3 \\
\text { vs } 4-5 \\
6 \text { months }\end{array}$ & $\begin{array}{l}\text { hyperglycemia (blood } \\
\text { glucose levels } \geq 200 \\
\mathrm{mg} / \mathrm{dl} \text { ) } \\
\text { Blood arterial samples }\end{array}$ & $\begin{array}{l}\text { Significant: } \\
\text { correlations: } \\
\text { Mortality rate with high BS }(\mathrm{p}<10 \mathrm{n}-4) \\
\text { A good outcome in } 71 \% \\
\text { Normoglycemic patients compared with } \\
32 \% \text { in other groups }(\mathrm{p}=0.03) \\
\end{array}$ \\
\hline $\begin{array}{l}\text { Samit et al. } 2010 \\
(53)\end{array}$ & $\begin{array}{l}\text { India; ? patiens, } 40 \text { completing, age } 15-50 \text { years. Inclusion GCS }> \\
\text { 9. admitted within } 6 \text { hours of injury, no gross systemic injury. } \\
\text { Exclusion: gross systemic injury, compound head injury, } \\
\text { comorbid illness, or cancer, psychiatric or other neurological } \\
\text { illnesses, shock, post-resuscitation, patients outside the time } \\
\text { frame }\end{array}$ & $\begin{array}{l}\text { GOS } 1-3 \\
\text { vs } 4-5 \\
3 \text { months }\end{array}$ & $\begin{array}{l}\text { serum } \mathrm{S}-100 \mathrm{~B} \text { and } \\
\text { NSE } \\
\text { days } 0,3,5 \text {. } \\
\text { Venous blood } \\
\text { samples }\end{array}$ & $\begin{array}{l}\text { Significant: } \\
\text { correlations; } \\
\text { A strong statistical significance exists } \\
\text { between day } 0 \text { serum levels of biochemical } \\
\text { markers and outcome assessment }(\mathrm{P}=.003 \\
\text { between GOS and S-100B and } \mathrm{P}<0.001 \\
\text { between GOS for NSE) }\end{array}$ \\
\hline $\begin{array}{l}\text { Melo et al. } \\
2010(38)\end{array}$ & $\begin{array}{l}\text { France, ?patients, } 315 \text { completing. Age } 1 \text { month to } 17 \text { years. } \\
\text { Inclusion: children }<17 \text { years of age who presented with a severe } \\
\text { TBI defined by an initial GCS } \leq 8 \text {. Exclusion: non-accidental } \\
\text { injury or initial GCS }>8\end{array}$ & mortality & $\begin{array}{l}\text { oxygen saturation, } \\
\text { blood } \\
\text { glucose levels, PT } \\
\text { at admission \& } \\
\text { every } 6 \text { hours }\end{array}$ & $\begin{array}{l}\text { 1.inadequate } \mathrm{SaO} 2 \text { increased the incidence } \\
\text { of death } \\
\text { 3-fold (odds ratio }=1.67 \text { ) } \\
\text { 2,3. hyperglycemia (odds ratio }=6.14 \text { ) and } \\
\text { severe coagulation disorders (odds ratio= } \\
\text { 3.10) increased the risk of death } 5 \text { times }\end{array}$ \\
\hline $\begin{array}{l}\text { Jackson da Silva } \\
\text { Gullo et al. } \\
2010(20)\end{array}$ & $\begin{array}{l}\text { Brazil, ? patients, } 83 \text { patients completing, age }>16 \text { years old, } \\
\text { Inclusion: severe TBI in ICU GCS } \leq 8 \text { gunshot injury and patients } \\
\text { who evolved to brain death before } 24 \text { hour of admission were } \\
\text { excluded }\end{array}$ & $\begin{array}{l}\text { Hospital } \\
\text { mortality }\end{array}$ & $\begin{array}{l}\text { serum PTX3 level } \\
\text { leukocytes count }\end{array}$ & $\begin{array}{l}\text { Elevated PTX3 significantly associated } \\
\text { with mortality }(\mathrm{P}<0.04) \\
\text { no differences in the leukocytes count }\end{array}$ \\
\hline $\begin{array}{l}\text { Kan et al. } \\
2009(14)\end{array}$ & $\begin{array}{l}\text { Malaysia, } 167 \text { patients, } 146 \text { completing,age } 2 \text { to } 16 \text { years. } \\
\text { Inclusion: head injury, severe TBI GCS } \leq 8 \text {. Exclusion: lost upon } \\
\text { follow up }\end{array}$ & $\begin{array}{l}\text { PCPC scores } 6 \\
\text { months }\end{array}$ & $\begin{array}{l}\text { serum glucose, PT and } \\
\text { a PTT ratio, INR, } \\
\text { platelet counts } \\
\text { and TWBC upon } \\
\text { admission }\end{array}$ & $\begin{array}{l}\text { Significant: } \\
\text { correlations; } \\
\text { serum glucose level }(\mathrm{P}=0.001), \text { TWBC } \\
\text { counts }(\mathrm{P}=0.04), \text { aPTT ratio }(\mathrm{P}=0.03), \mathrm{PT} \\
\text { ratio }(\mathrm{P}<0.001), \text { INR }(\mathrm{P}=0.009)\end{array}$ \\
\hline $\begin{array}{l}\text { WhaSook et al. } \\
2009(72)\end{array}$ & $\begin{array}{l}\text { Republic of Korea, } 190 \text { patients, } 82 \text { TBI. Age }>18 \text { inclusion: } \\
\text { adult }>18 \text { years, TBI or hemorrhagic stroke who were admitted } \\
\text { within } 24 \text { hours of injury at the ICU }\end{array}$ & $\begin{array}{l}\text { GOS } \\
\text { mortality } 6 \\
\text { months }\end{array}$ & $\begin{array}{l}\mathrm{Hct}, \mathrm{PaO} 2, \mathrm{PaCO} 2, \\
\text { serum osmolality, } \mathrm{pH} \text {, } \\
\text { total cholesterol and } \\
\text { glucose levels on } \\
\text { admission }\end{array}$ & $\begin{array}{l}\text { The identified predictors of mortality } \\
\text { for patients with } \mathrm{TBI}: \mathrm{PaO} 2(\mathrm{~F}=11.83 \text {, } \\
\mathrm{p}=0.00), \mathrm{PaCO} 2(\mathrm{~F}=4.40, \mathrm{p}=0.02) \text { on } \\
\text { admission } \\
\text { Others: non-significant }\end{array}$ \\
\hline $\begin{array}{l}\text { Seif El-Deenet al. } \\
2009 \text { (4) }\end{array}$ & $\begin{array}{l}\text { Egypt, ? patiens, } 40 \text { completing, age } 26-61 \text { years. Inclusion: } \\
\text { head injury and presentation within } 6 \mathrm{~h} \text {. Exclusion: history of } \\
\text { Alzheimer's disease, Down's syndrome, multiple sclerosis, } \\
\text { schizophrenia, depression, cerebral stroke, spinal cord injury } \\
\text { were excluded }\end{array}$ & \begin{tabular}{|l|} 
Expanded \\
Disability Status \\
Scale (EDSS) \\
6 months \\
unfavorable \\
$:$ EDSS $\geq 5$ \\
\end{tabular} & $\begin{array}{l}\text { Serum S100 B Protein } \\
\text { venous blood sample }\end{array}$ & $\begin{array}{l}\text { Significant } \\
\text { correlation: Serum S100 B increased in non- } \\
\text { survivors and in patients with unfavorable } \\
\text { outcome }\end{array}$ \\
\hline
\end{tabular}




\begin{tabular}{|c|c|c|c|c|}
\hline Author(s) & Patient Characteristics & Outcome & Factor & Result \\
\hline $\begin{array}{l}\text { Helmyet al. } \\
2009(50\end{array}$ & $\begin{array}{l}\text { United Kingdom, } 367 \text { patients, } 327 \text { patients completing. Age } \\
=>16 \text { years. Inclusion: head trauma }\end{array}$ & $\begin{array}{l}\text { GOS } 1-3 \\
\text { vs } 4-5\end{array}$ & $\begin{array}{l}\text { Na, potassium, } \\
\text { glucose, alb, corrected } \\
\text { calcium, phosphate, } \\
\text { serum osmolarity, } \\
\text { creatine kinase, } \\
\text { magnesium, Hb, } \\
\text { WBC,PT,APTT, CRP }\end{array}$ & $\begin{array}{l}\text { Significant: raised serum glucose, low } \\
\text { haemoglobin } \\
\text { The remaining five variables only had a } \\
\text { statistical relationship with outcome via at } \\
\text { least one other variable. }\end{array}$ \\
\hline $\begin{array}{l}\text { Melo et al. } \\
2009(54)\end{array}$ & $\begin{array}{l}\text { France, } 58 \text { patients, age below } 6 \text { years. with severe head trauma } \\
\text { defined by an initial GCS } \leq 8\end{array}$ & mortality & $\begin{array}{l}\text { Elevated blood } \\
\text { glucose \& coagulation } \\
\text { Disorders in first } 48 \mathrm{~h} \\
\text { defined as a BS } \geq 200 \\
\mathrm{mg} / \mathrm{dL} \& \mathrm{PT}<50 \%\end{array}$ & $\begin{array}{l}\text { Significant } \\
\text { correlation: glucose level } \geq 200 \mathrm{mg} / \mathrm{dL} \text { with } \\
\text { mortality rate }(\mathrm{p}=0.02) \text { and coagulation } \\
\text { disorders with mortality rate }(\mathrm{p}=0.02) \text {. }\end{array}$ \\
\hline $\begin{array}{l}\text { Griesdale } \\
\text { et al. } 2009 \text { (36) }\end{array}$ & $\begin{array}{l}\text { Canada, } 273 \text { patients, } 170 \text { patients. Mean age, } 38 \text { years. } \\
\text { completing. Inclusion: admitted to the ICU severe TBI }(\mathrm{GCS}<8) \text {. } \\
\text { Exclusion :obeying within } 12 \mathrm{~h} \text {, indicating a non-severe TBI, } \\
\text { died within } 12 \text { hour, non-traumatic etiology of the neurologic } \\
\text { injury or concomitant highcervical spine injury }\end{array}$ & $\begin{array}{l}\text { hospital } \\
\text { mortality }\end{array}$ & $\begin{array}{l}\text { Hyperglycemia was } \\
\text { defined as serumblood } \\
\text { glucose }>11.1 \mathrm{mmol} / 1 \\
(200 \mathrm{mg} / \mathrm{dl}) \\
\text { Venous blood samples }\end{array}$ & $\begin{array}{l}\text { Significant correlation: } \\
\text { Any episode of hyperglycemia ( }>200 \mathrm{mg} / \\
\text { dl) with } 3.6 \text {-fold increased risk of hospital } \\
\text { mortality }\end{array}$ \\
\hline Liu et al. 2009 (35) & $\begin{array}{l}\text { United states, } 429 \text { patients, } 380 \text { completing, age }>18 \text { years. Inclusion: } \\
\text { TBI, }>18 \text { years of age, admitted to the ICU within } 24 \text { h of injury, and } \\
\text { required ICU care for more than } 24 \text { hour. Exclusion: a glucose level } \\
\text { reading was not recorded within the first } 24 \mathrm{~h}\end{array}$ & $\begin{array}{l}\text { hospital } \\
\text { mortality }\end{array}$ & $\begin{array}{l}\text { Blood Glucose } \\
\text { During the first } 5 \\
\text { consecutive ICU days } \\
\text { Venous blood samples }\end{array}$ & $\begin{array}{l}\text { Non-survivors had significantly higher } \\
\text { glucose levels on admission and first day } \\
\text { glucose cut-off values of } 135 \mathrm{mg} / \mathrm{dl} \text { for } \\
\text { admission and } 160 \mathrm{mg} / \mathrm{dl} \text { for day-1 peak }\end{array}$ \\
\hline $\begin{array}{l}\text { Salehpoor et al. } \\
2009(15)\end{array}$ & $\begin{array}{l}\text { Iran,? Patients, } 96 \text { completing. Age } 3-75 \text { years. Inclusion: severe } \\
\text { head injuries admitted to our neurosurgical department and } \\
\text { laidup in the trauma and ICU sections }\end{array}$ & $\begin{array}{l}\text { GOS } 1-3 \text { vs } \\
4-5 \text { at discharge } \\
\text { and } 6 \text { months }\end{array}$ & serum glucose levels & $\begin{array}{l}\text { Significant: correlations: between good } \\
\text { outcome }(G O S=4,5) \text { and poor outcome } \\
(G O S=1,2) \text { and mean blood sugar amount } \\
(p=0.006)\end{array}$ \\
\hline $\begin{array}{l}\text { Nyle'n et al. } 2008 \\
(52)\end{array}$ & $\begin{array}{l}\text { Sweden, } 222 \text { patients, } 73 \text { completing, age below } 15 \text { years. } \\
\text { Inclusion: severe TBI admitted to NICU, Reaction Level Scale } \\
\text { (RLS) } \geq 4 \text {, corresponding GCS } \leq 8 \text {, therapeutic indication to } \\
\text { monitor ICP, Need for ventilator, living in Sweden, first blood } \\
\text { sample obtained } \leq \text { day } 2\end{array}$ & $\begin{array}{l}\text { GOS } 1-3 \\
\text { vs } 4-5\end{array}$ & $\begin{array}{l}\text { Serum levels of } \\
\text { S100B, S100A1B and } \\
\text { S100BB } \\
\text { Venous blood samples }\end{array}$ & $\begin{array}{l}\text { Patients with an unfavorable outcome had } \\
\text { significantly increased maximum levels of } \\
\text { S100B }(p<0.05), \text { S100A1B }(p<0.01) \text { and } \\
\text { S100BB }(p<0.01)\end{array}$ \\
\hline $\begin{array}{l}\text { Rainey et al. } 2008 \\
(63)\end{array}$ & $\begin{array}{l}\text { United kingdom,? Patients, } 100 \text { completing. Age: } 16-86 \text { years. } \\
\text { Inclusion : aged } \geq 16 \text { years with severe head trauma, admitted to } \\
\text { ICU within } 24 \text { hours of injury. Exclusion: Late referrals to ICU } \\
(\geq 24 \mathrm{~h})\end{array}$ & $\begin{array}{l}\text { GOS } 1-3 v s \\
4-53 \text {-months }\end{array}$ & $\begin{array}{l}\text { S100b } 24 \text { harterial } \\
\text { blood samples }\end{array}$ & $\begin{array}{l}\text { Significant: correlations: } \\
\text { S100b higher in unfavorable } \\
\text { outcome }(p=0.000) \& \text { in who died }(p= \\
0.003)\end{array}$ \\
\hline $\begin{array}{l}\text { Meier et al. } \\
2008(16)\end{array}$ & $\begin{array}{l}\text { Switzerland, } 320 \text { patients, } 228 \text { patients completing, age } 18-81 \\
\text { years Inclusion: severe TBI treated on ICU }>24 \mathrm{~h} \text {. ICP probe } \\
\text { placed in first } 8 \text { hours. Exclusion: died in first } 24 \mathrm{~h} \text {, without ICP } \\
\text { probe, incomplete data }\end{array}$ & $\begin{array}{l}\text { Mortality and } \\
\text { length of ICU } \\
\text { stay }\end{array}$ & $\begin{array}{l}\text { Arterial blood glucose } \\
\text { levels during the first } \\
2 \text { weeks }\end{array}$ & $\begin{array}{l}\text { Non-significant: correlations: Overall } \\
\text { mortality rates and ICU stay with BS }\end{array}$ \\
\hline $\begin{array}{l}\text { Guzel et al. } \\
2008(24)\end{array}$ & $\begin{array}{l}\text { Turkey, ? Patients, } 169 \text { completing. Age } 1 \text { to } 75 \text { years. Inclusion: } \\
\text { isolated head injury Exclusion: major health problems: DM, } \\
\text { renal or cardiac failure, CNS diseases, and bleeding disorders, } \\
\text { concomitant extracranial injury, spinal cord damages, alcohol } \\
\text { intoxications, injury more than } 24 \mathrm{~h} \text { ago, Hx of neurological } \\
\text { or neuropsychiatric disorders, alcohol, drug, substance abuse, } \\
\text { previous TBI }\end{array}$ & $\begin{array}{l}\text { outcome within } \\
\text { the first } 24-48 \\
\text { h after trauma } \\
\text { (short-term } \\
\text { outcome), } \\
\text { and GCS and } \\
\text { mortality } 30 \\
\text { days after } \\
\text { trauma } \\
\end{array}$ & $\begin{array}{l}\text { Serum NSE, the first } \\
\text { 2(NSE1), } 24 \text { (NSE2), } \\
48 \text { (NSE3)hours } \\
\text { venous blood } \\
\text { samples }\end{array}$ & $\begin{array}{l}\text { The levels of NSE were significantly higher } \\
\text { in who died in } 30 \text { days after trauma or GCS } \\
\text { lower than or equal to } 8(\mathrm{p}<0.001)\end{array}$ \\
\hline $\begin{array}{l}\text { Lilianget al. } \\
2008 \text { (18) }\end{array}$ & $\begin{array}{l}\text { Taiwan, ? Patients, } 44 \text { completing. Age }>18 \text { years. Inclusion: } \\
\text { severe closed head injury admitted to NICU, within } 6 \mathrm{~h} \text { of injury } \\
\text { Exclusion: age }<18 \mathrm{y} \text {, unavailability of blood sample or informed } \\
\text { consent or outcome data of } 6 \text {-mo. neurologic disabilities prior } \\
\text { to injury, brought more than } 6 \mathrm{~h} \text { after injury, prolonged cardiac } \\
\text { arrest, high cervical spinal cord injury, died from controllable } \\
\text { hemorrhage or multiple life-threatening injuries }\end{array}$ & $\begin{array}{l}\text { GOS } 1-3 \\
\text { vs } 4-5 \\
6 \text { months }\end{array}$ & $\begin{array}{l}\text { tau protein level, } \\
\text { Venous blood samples }\end{array}$ & $\begin{array}{l}\text { Significant: correlations: } \\
\text { high serum tlevels (P } 1 / 40.043 \text { ) were the } \\
\text { independent prognostic factorsfor a poor } \\
\text { outcome }\end{array}$ \\
\hline $\begin{array}{l}\text { Salim et al. } \\
2008(63)\end{array}$ & $\begin{array}{l}\text { United states, } 1,221 \text { patients, } 420 \text { completing, age }>18 \text { years. } \\
\text { Inclusion: blunt trauma with severe TBI (head Abbreviated } \\
\text { Injury Scale score }[\mathrm{AIS}] \geq 3 \text { ) admitted to the Surgical Intensive } \\
\text { Care Unit (SICU); with serial cTnI measurements. Exclusion: } \\
\text { non-survivable head injuries (head AIS score }>6 \text { ), significant } \\
\text { extracranial injury (AIS score }>3 \text { ), died within } 24 \text { hours. }\end{array}$ & $\begin{array}{l}\text { hospital } \\
\text { mortality }\end{array}$ & $\begin{array}{l}\text { serial cTnI } \\
\text { measurements } \\
\text { during the first } 24 \text { to } \\
48 \text { hours }\end{array}$ & $\begin{array}{l}\text { Significant correlation: } \\
\text { Elevated peak troponin with mortality } \\
(p<0.0001) \text {; Whereas admission troponin } \\
\text { elevation was not }(p=0.01)\end{array}$ \\
\hline $\begin{array}{l}\text { Mowery et al. } \\
2007 \text { (2) }\end{array}$ & $\begin{array}{l}\text { United states, } 977 \text { patients, } 160 \text { completing. Age: } 38-73 \text { years, } \\
\text { Inclusion: All critically ill, mechanically ventilated patients } \\
\text { with IV insulin administration for glucose above } 110 \mathrm{mg} / \mathrm{dL} \text { and } \\
\text { repeating 2-hour glucose sampling and insulin adjustments. }\end{array}$ & $\begin{array}{l}\text { hospital } \\
\text { mortality }\end{array}$ & $\begin{array}{l}\text { 2-hour glucose } \\
\text { sampling }\end{array}$ & $\begin{array}{l}\text { The median blood glucose was statistically } \\
\text { different but not clinically different among } \\
\text { the patients who lived and died (114; } \\
\text { interquartile range, } 109-132 \text { vs. } 118 ; 111- \\
136, p=0.01) \text {. }\end{array}$ \\
\hline
\end{tabular}




\begin{tabular}{|c|c|c|c|c|}
\hline Author(s) & Patient Characteristics & Outcome & Factor & Result \\
\hline $\begin{array}{l}\text { Beers et al. } \\
2007 \text { (6) }\end{array}$ & $\begin{array}{l}\text { United states,? patients, } 30 \text { completing. Age }<3 \text { years. Inclusion: } \\
\text { head injury, severe TBI GCS }=<8 \text { ). admitted within } 3 \text { hours of } \\
\text { injury }\end{array}$ & $\begin{array}{l}\text { GOS } \\
\text { IQ measure }\end{array}$ & $\begin{array}{l}\text { NSE, S100B, and } \\
\text { MBP }\end{array}$ & $\begin{array}{l}\text { NSE, S100B, and MBP levels significantly } \\
\text { correlated with poorer outcome. } p<0.05\end{array}$ \\
\hline $\begin{array}{l}\text { Llompart-Pouet al. } \\
2007 \text { (37) }\end{array}$ & $\begin{array}{l}\text { Spain, ? patients, } 50 \text { completing. Age: 16-77 years } \\
\text { Inclusion:isolated TBI admitted to ICU, intubated, mechanically } \\
\text { ventilated, and had ICP monitoring. Exclusion: }<16 \text { years, lack } \\
\text { of indication to measure ICP, injury of other organs, probability } \\
\text { of survival < }<48 \text { hours, previous use of drugs known to affect } \\
\text { cortisol secretion (corticosteroids, etomidate), septic shock. }\end{array}$ & $\begin{array}{l}\text { ICU } \\
\text { survival rates }\end{array}$ & $\begin{array}{l}\text { plasma ACTH levels, } \\
\text { baseline and } \\
\text { stimulated } \\
\text { serum cortisol } \\
\text { after a high-dose } \\
\text { corticotrophin } \\
\text { stimulation test }\end{array}$ & $\begin{array}{l}\text {-low ACTH values }(<9 \mathrm{pg} / \mathrm{mL}) \text { : lower } \\
\text { mortality }(\mathrm{p}<0.0001) \\
\text {-low plasma ACTH +higher survival: } \\
\text { increased ICU length of stay }(\mathrm{p}<0.03) \text {. } \\
\text {-No significant differences with other } \\
\text { related variables }\end{array}$ \\
\hline $\begin{array}{l}\text { Yurgel et al. } \\
2007 \text { (3) }\end{array}$ & $\begin{array}{l}\text { Brazil ? patients, } 41 \text { completing, age } 18-64 \text { years. Inclusion: } \\
41 \text { male victims of severe TBI (GCS } 3-8 \text { at the emergency } \\
\text { room admission, without previous history of neurological or } \\
\text { psychiatric Disease. who transferred to the ICU within } 24 \text { hours } \\
\text { of the head injury }\end{array}$ & $\begin{array}{l}\text { GOS } 1 \\
\text { vs } 2-5\end{array}$ & $\begin{array}{l}\text { Plasma DNA } \\
\text { at study entry\& } 24 \mathrm{~h} \\
\text { after }\end{array}$ & $\begin{array}{l}\text { significant correlation: higherDNA } \\
\text { concentrations and fatal outcome } 24 \mathrm{~h} \\
\text { after study entry }(\mathrm{p}=0.03)\end{array}$ \\
\hline $\begin{array}{l}\text { Bayir et al. } \\
2006(10)\end{array}$ & $\begin{array}{l}\text { Turkey, ? patients, } 15 \text { completing,age } 2-73 \text { years. Inclusion: } \\
\text { isolated head injury, admitted within } 3 \text { hours of injury. Exclusion } \\
\text { criteria were multisystem trauma, existing coagulation disorders } \\
\text { and presentation after the first three hours }\end{array}$ & Mortality & $\begin{array}{l}\text { platelet number (Plt), } \\
\text { PT, PTT, fibrinogen, } \\
\text { fibrin degradation } \\
\text { products (FDP) and } \\
\text { D-dimer levels } \\
\text { venous blood samples } \\
\end{array}$ & $\begin{array}{l}\text { Significant: correlations; } \\
\text { Mortality with PT, FDP and D-dimer } \\
(\mathrm{P}<0.001, \quad \mathrm{P}<0.001 \quad \text { and } \mathrm{P}<0.001 \text {, } \\
\text { respectively). And with Plt }(\mathrm{p}=0.007) \\
\text { Not Significant: } \mathrm{PTT}(\mathrm{p}=0.1)\end{array}$ \\
\hline $\begin{array}{l}\text { Naeimi et al. } \\
2006(45)\end{array}$ & $\begin{array}{l}\text { Austria, ? patients, } 45 \text { completing. Age }>16 \text { years. Inclusion: } \\
\text { head injury, admitted within } 3 \text { hours of injury }\end{array}$ & $\begin{array}{l}\text { 1.minor and } \\
\text { severe head } \\
\text { injuries } \\
\text { 2.a cerebral } \\
\text { pathological } \\
\text { finding in CT } \\
\text { scans }\end{array}$ & $\begin{array}{l}\text { Serum S-100B and } \\
\text { NSE proteins } \\
\text { Venous blood samples } \\
\text { admission and every } \\
24 \mathrm{~h} \text { for } 7 \text { days }\end{array}$ & $\begin{array}{l}\text { a significant difference between the S-100B } \\
\text { serum concentration and the two groups- } \\
\text { minor head injuries and severe head injuries. } \\
\text { A statistically significant correlation was } \\
\text { observed between an increase of S-100B } \\
\text { and NSE serum values and a cerebral } \\
\text { pathological finding in CT scans }\end{array}$ \\
\hline $\begin{array}{l}\text { Nyle'n et al. } \\
2006(56)\end{array}$ & $\begin{array}{l}\text { Sweden, } 222 \text { patients, } 73 \text { completing, age below } 15 \text { years. } \\
\text { Inclusion: severe TBI admitted to NICU, Reaction Level Scale } \\
\text { (RLS) } \geq 4 \text {, corresponding GCS } \leq 8 \text {, therapeutic indication to } \\
\text { monitor ICP, Need for ventilator. Only patients living in Sweden } \\
\text { included. First blood sample had to be obtained on day } 2 \text { at the latest }\end{array}$ & $\begin{array}{l}\text { GOS } 1-3 \\
\text { vs } 4-5 \\
1 \text { year }\end{array}$ & $\begin{array}{l}\text { Venous blood } \\
\text { samples for GFAP } \\
0,1,2,3,4,6,8 \text { and } \\
\text { once in between days } \\
11 \text { and } 14 . \\
\end{array}$ & $\begin{array}{l}\text { Significant: } \\
\text { unfavorable outcome : } \\
(\mathrm{p}<0.001) \text { higher maximal s-GFAP }\end{array}$ \\
\hline $\begin{array}{l}\text { Salim et al. } \\
2005(7)\end{array}$ & $\begin{array}{l}\text { United states, } 1221 \text { patients, } 834 \text { ompleting, age }>18 \text { years. Inclusion: } \\
\text { blunt trauma with severe traumatic brain injury (head Abbreviated } \\
\text { Injury Score } \geq 3 \text { ) admitted to SICU. Exclusion: who died within } 48 \mathrm{~h} \text {, } \\
\text { non-survivable head injuries (head AIS }=6 \text { ), significant extracranial } \\
\text { injury (AIS }>3 \text { for other anatomical regions) }\end{array}$ & mortality & $\begin{array}{l}\text { Admission and daily } \\
\text { blood glucose yp to } \\
7 \text { days }\end{array}$ & $\begin{array}{l}\text { Persistent hyperglycemia significantly } \\
\text { higher mortality ( } 64 \% \text { ví } 21 \%, \mathrm{P}<0.0001) \text {. } \\
\text { Excluding deaths, relation with the hospital } \\
\text { length of stay and intensive care unit length } \\
\text { of stay: not significant }\end{array}$ \\
\hline $\begin{array}{l}\text { Jeremitsky } \\
\text { et al. } 2005 \text { (29) }\end{array}$ & $\begin{array}{l}\text { United states, } 121 \text { patients, } 77 \text { completing, age }>18 \text { years. } \\
\text { Inclusion: TBI, GCS of } 8 \text { or less who survivedfor } 5 \text { days or more. } \\
\text { Exclusion: medical record lacked complete data, or if the GCS } \\
\text { improved to } 13 \text { or higher over the initial } 24 \text { hours }\end{array}$ & $\begin{array}{l}\text { hospital } \\
\text { mortality } \\
\text { hospital LOS } \\
\text { day } 5 \text { GCS }\end{array}$ & $\begin{array}{l}\text { highest daily serum } \\
\text { glucose (mg/dL) } \\
\text { Hyperglycemia was } \\
\text { defined as a serum } \\
\text { glucose level of } \\
170 \mathrm{mg} / \mathrm{dL} \text { or higher }\end{array}$ & $\begin{array}{l}\text { worse survival for the individuals with } \\
\text { an HS }(\mathrm{p}<0.03 \text {; HS were independent } \\
\text { predictors of lower day } 5 \text { GCS, whereas } \\
\text { HS 3-5 and day } 4 \text { GCS were related to } \\
\text { prolonged hospital length of stay }\end{array}$ \\
\hline $\begin{array}{l}\text { Nelson et al } \\
2005(49)\end{array}$ & $\begin{array}{l}\text { Sweden, ? patients, } 757 \text { completing. Age }<18 \text {. Inclusion: }>18 \\
\text { years, evaluated within } 24 \text { hours of sustaining TBI, requiring } \\
\text { a CT scan. Exclusion: penetrating TBIs, intentional head } \\
\text { trauma,multisystem injuries, pelvic or lower extremity fractures, } \\
\text { spinal cord injuries or bleeding disorders, cerebral palsy, mental } \\
\text { retardation, developmental delay, or ventricular shunts }\end{array}$ & GOS & $\begin{array}{l}\text { Serum Glucose, } \\
\text { Creatinine, albumin, } \\
\text { hemoglobin, and } \\
\text { osmolarity levels }\end{array}$ & $\begin{array}{l}\text { Creatinine: an independent predictor of TBI } \\
\text { outcome. Glucose, albumin, and osmolarity } \\
\text { levels were also identified as predictors, } \\
\text { depending on analysis method. A worse } \\
\text { outcome related to increasing osmolarity. } \\
\text { hemoglobin was not found significant when } \\
\text { adjusted for post-resuscitation GCS }\end{array}$ \\
\hline $\begin{array}{l}\text { Pelinka et al. } \\
2005(29)\end{array}$ & $\begin{array}{l}\text { Germany. ? patiens, } 92 \text { completing, age? Med } 39 \text { years. Inclusion: } \\
\text { TBI with or without multiple trauma }<12 \mathrm{~h} \text { before admission } \\
\text { verified by CT }\end{array}$ & $\begin{array}{l}\text { GOS } \\
3 \text { months } \\
1 \text { vs } 4-5\end{array}$ & $\begin{array}{l}\text { Venous blood for } \\
\text { GFAP and S100B } \\
\text { daily }\end{array}$ & $\begin{array}{l}\text { GFAP \&S100B: lower in GOS } 4-5 \text { than in } \\
\text { GOS } 1(\mathrm{p}<0.0005) \text {. GFAP, but not S100B, } \\
\text { was low-er in GOS } 4-5 \text { than in GOS } 2-3 \\
(\mathrm{p}<0.05)\end{array}$ \\
\hline $\begin{array}{l}\text { Salehpoor et al. } \\
2005(15)\end{array}$ & $\begin{array}{l}\text { Iran, ? patients, 30completing. Age 9-90 years; Inclusion: } \\
\text { Head trauma GCS } \leq 8 \text {. All of them were in intensive care unit } \\
\text { Exclusion: Multiple trauma patients were omitted }\end{array}$ & $\begin{array}{l}\text { GOS } 1-3 \\
\text { vs } 4-5\end{array}$ & \begin{tabular}{|l} 
LDH level \\
Venous blood samples
\end{tabular} & $\begin{array}{l}\text { Significant: meaningful relation: change of } \\
\text { LDH level }(\mathrm{At}=4, \mathrm{P}<0.01) \text {. }\end{array}$ \\
\hline
\end{tabular}

\section{References}

1. Goyal A, Carter M, Niyonkuru C, Fabio A, Amin K Berger RP, Wagner AK M D. S100b as a Prognostic Biomarker in Outcome Prediction for Patients with Severe TBI. J Neurotrauma. 2013;30(11):946-57.

2. Mowery NT. Stress Insulin Resistance is a Marker for Mortality in Traumatic Brain Injury. J Trauma. 2009:66(1):145-51; 151-3.

3. CampelloYurgel V, Ikuta N, Brondani da Rocha A Lunge VR, Fett Schneider R, Kazantzi Fonseca AS, et al. Role of Plasma DNA as a Predictive Marker of Fatal Outcome following Severe Head Injury in Males. J Neurotrauma. 2007;24(7):1172-81. Available from: http:// Neurotrauma. 2007;24(7):1172-81.
dx.doi.org/10.1089/neu.2006.0160
4. Ali E. Seif El-Deen, Said Hammad. Preoperative Serum S100 B Protein as a Prognostic Marker for Traumatic Brain Injury Patients. E.J.N.S. 2009;24 (1)135-152.

5. DeFazio MV, Rammo RA, Robles JR, Bramlett HM Dietrich WD, Bullock MR. The Potential Utility of Blood Dietrich WD, Bullock MR. The Potential Utility of Blood-
Derived Biochemical Markers as Indicators of Early Derived Biochemical Markers as Indicators of Early Clinical Trends Following Severe Traumatic Brain Injury.
World Neurosurgery. 2014:81(1):151-8. Available from: World Neurosurgery. 2014;81(1):151-8. Avala
http://dx.doi.org/10.1016/j.wneu.2013.01.015

6. Beers SR, Berger RP, Adelson PD. Neurocognitive outcome and serum biomarkers in inflicted versus non-inflicted traumatic brain injury in young children. $J$ Neurotrauma. 2007;24(1):97-105.
7. A.Salim. Persistent Hyperglycemia in Severe Traumatic Brain Injury: An Independent Predictor of Outcome. Am Surg. 2009;75(1):25-9

8. Gopcevic A. Plasma interleukin-8 as a potential predictor of mortality in adult patients with severe traumatic brain injury. Tohoku J Exp Med. 2007;211(4):387-93.

9.Liu L, Wei H, Chen F, Wang J, Dong JF, Zhang J. Endothelial progenitor cells correlate with clinical outcome of traumatic brain injury. Crit Care Med. 2011:39(7):1760-

10. Bayir A, Kalkan E, Kocak S, Ak A, Cander B, Bodur S Fibrinolytic markers and neurologic outcome in traumatic brain injury. Neurol India.2006;54:363-5. 
11.Copin H.Matrix metalloproteinase 9 and cellular fibronectin plasma concentrations are predictors of the composite endpoint of length of stay and death in the intensive care unit after severe traumatic brain injury. Scandinavian Journal of Trauma, Resuscitation and Emergency Medicine.2012;43(6): 23-27.

12.Meshkini A,Salehpour F. Relationships of hyperglycemia and neurological outcome in patients with head injury.Anesthesia.2007;43(2): 2-6.

13. Douglas D. Fraser. Severe traumatic brain injury in children elevates glial fibrillary acidic protein in cerebrospinal fluid and serum. Pediatr Crit Care Med.2011;32(6):33-36.

14. Choon Hong Kan, MohdSaffari, TeikHooiKhoo. Prognostic Factors of Severe Traumatic Brain Injury Outcome in Children Aged 2-16 Years at A Major Outcome in Children Aged 2-16 Years at A Major
Neurosurgical Referral Centre. Malaysian Journal of Neurosurgical Referral Centre. Mal
Medical Sciences.2009;16(4):25-33.

15. SalehpoorF, Meshkini A. Prognostic value of serum $\mathrm{DH}$ in head trauma. The International Medical Journal. 2005;4(2)31-37.

16. Meier R. Differential temporal profile of lowered blood glucose levels $(3.5$ to $6.5 \mathrm{mmol} / \mathrm{l}$ versus 5 to 8 $\mathrm{mmol} / \mathrm{l})$ in patients with severe traumatic brain injury. Crit Care.2008;12(4):98-102.

17. Hohl E. Plasma levels of oxidative stress biomarkers and hospital mortality in severe head injury: A multivariate analysis. Journal of Critical Care 27, 523 e11-523.e19;2012.

18.Liliang PC. Tau Proteins in Serum Predict Outcome After Severe Traumatic Brain Injury.Journal of Surgical Research. 2010;160(5):302-307.

19. Hossam M, Jehan H. Sabry, Deena A. El-Shabrawy. The Predictability of at Admission Serum GFAP and S100 protein Levels for the Outcome of Traumatic Brain Injury Patients. Egy. J. Neur. Surg. 2011;26(1):50-56.

20. Gullo J da S, Bertotti MM, Silva CCP, Schwarzbold M, Diaz AP, Soares FMS, et al. Hospital Mortality of Patients with Severe Traumatic Brain Injury is Associated with Serum PTX3 Levels. Neurocrit Care. 2010; 23;14(2):194-9. Available from: http://dx.doi. org/10.1007/s12028-010-9462-y.

21.Greuters. Acute and delayed mild coagulopathy are related to outcome in patients with isolated traumatic. brain injury.Crit Care.2011;15(1):2

22.StefaniaM. Neuronal and glial markers are differently associated with computed tomography findings and outcome in patients with severe traumatic brain injury: a case control study. Critical Care.2012;15(1):156-159.

24. Guzel A.Serum neuron-specific enolase as a predictor of short-term outcome and its correlation with Glasgow Coma Scale in traumatic brain injury. Neurosurg Glasgow Coma Scale in

25. Zitnay GA, Zitnay KM, Povlishock JT, Hall ED, Marion DW, Trudel T, et al. Traumatic Brain Injury Research Priorities: The Conemaugh International Brain Injury Symposium. Journal of Neurotrauma 2008;25(10):1135-52. Available from: http://dx.doi. org/10.1089/neu.2008.0599

26. Hada M. Role of early cell-free DNA levels decrease as a predictive marker of fatal outcome after severe traumatic brain injury. ClinicaChimica Acta.2012; 414 12-17.

27.Lanier WL, StanglandKJ ,Scheithaure BW. The effects of dextrose infusion and head position on neurologic outcome after complete cerebral ischemia in primates: examination of a model. Anesthesiology.1987;66:39-48.

28.Chabok SY, Moghadam AD, Saneei Z, Amlash G, Leili EK, Amiri ZM. Neuron-specific enolase and S100BB as outcome predictors in severe diffuse axonal injury. Journal of Trauma and Acute Care Surgery. 2012;72(6):1654-7. Available from: http://dx doi. org/10.1097/ta.0b013e318246887e

29.Pelinka LE, Kroepfl A, Leixnering M, Buchinger W, Raabe A. Redl H. GFAP Versus S100B in Serum after Traumatic Brain Injury: Relationship to Brain Damage and Outcome. Neurotrauma. 2004; 21(11):1553-61. Available from: http:// Neurotrauma. 2004; 21(11):1553-61. Ava

30. Smith A.Relationship between hyperglycemia and outcome in children with severe traumatic brain injury. PediatrCrit Care Med.2012;13(1):85-91.

31. Lin C, Huang SJ, Wang N, Shen ZP. Relationship between plasma leptin levels and clinical outcomes.

32.Turgeon AF, Lauzier F, Burns KEA, Meade MO Scales DC, Zarychanski R. Determination of neurologica prognosis in adult patients with severe traumatic brain injury: a survey of Canadian intensivists, neurosurgeons and neurologists. Crit Care Med ,epub ahead of print 2013

33. HergenroederG.W. Serum IL-6: a candidate biomarker for intracranial pressure elevation following isolated traumatic brain injury. Journal of Neuroinflammation.2010;3:7-19.

34. Jeremitsky E. The Impact of Hyperglycemia on Patients with Severe Brain Injury. J Trauma. Jan.2005;58(1):31-36.

35. Liu D.Clinical Impact of Early Hyperglycemia during Acute Phase of Traumatic Brain Injury.Neurocrit Care.2009;11:151-157.

36. Donald E. G. Griesdale, Marie-He'le'ne Tremblay, Jonathan McEwen, Dean R. Chittock. Glucose Contro and Mortality in Patients with Severe Traumatic Brain Injury. Neurocrit Care.2009:11:311-316.

37. Llompart-Pou JA. Relationship between plasma adrenocorticotropin hormone and intensive care unit survival in early traumatic brain injury. J Trauma.2007;62(6):1457-61. 38.Tude M. Mortality in Children with Severe Head
Trauma: Predictive Factors and Proposal for a New Trauma: Predictive Factors and Proposal for a
Predictive Scale. Neurosurgery.2010;67(6):1542-7.

39. Hossam M, Jehan H. Sabry, Deena A. El-Shabrawy. The Predictability of at Admission Serum GFAP and S100 protein Levels for the Outcome of Traumatic Brain Injury Patients. Egy. J. Neur. Surg.2011;26(1);11-19.

40.Matsushima K, Peng M, Velasco C, Schaefer E, Diaz Arrastia $R$, Frankel $H$. Glucose variability negatively impacts long-term functional outcome in patients with traumatic brain injury. J Crit Care.2012;27(2):125-31. 41. Žurek J, Bartlová L, Fedora M.
Hyperphosphorylatedneurofilament NF-H as a predictor of mortality after brain injury in children. Brain Injinforma Healthcare; 2011;25(2):221-6. Available from: http:/l dx.doi.org/10.3109/02699052.2010.541895

42.Amy K., Wagner. Acute Serum Hormone Levels: Characterization and Prognosis after Severe Traumatic Brain Injury. J Neurotrauma.2011;28(6): 871-888.

43. Olivecrona M, Rodling-Wahlstrom M, Naredi S, Koskinen L-OD. S-100B and neuron specific enolase are poor outcome predictors in severe traumatic brain injury treated by an intracranial pressure targeted therapy. Journal of Neurology, Neurosurgery \& Psychiatry. BMJ;2009;80(11):1241-8. Available from: http://dx.doi. org/10.1136/jnnp.2008.158196

44. SaadatS. Association of persistent hyperglycemia with outcome of severe traumatic brain injury in pediatric with outcome of severe traumatic brain injury in pediation. Childs Nerv Syst.2012; 28:1773-1777.

45. Naeimi ZS, Weinhofer A, Sarahrudi K, Heinz T, Vécsei $V$. Predictive value of $S-100 B$ protein and neuron specific-enolase as markers of traumatic brain damage in clinical use. Brain Inj. Informa UK Limited 2006;20(5):463-8. Available from: http://dx.doi. org/10.1080/02699050600664418

46.CzeiterR. Brain Injury Biomarkers May Improve the Predictive Power of the IMPACT Outcome Calculator Journal of Neurotrauma.2012; 29:1770-1778

47. Nazik A, Fatih T, Muhammet Ş. Admission hyperglycemia is a reliable outcome predictor in children with severe traumatic brain injury. J Pediatr (Rio J).2011;87(4):325-8.

48. Salim A. Significance of Troponin Elevation afte Severe Traumatic Brain Injury. J Trauma.2008; 64(1):46 52.

49. Nelson DW, Rudehill A, MacCallum RM, Holst A, Wanecek M, Weitzberg $E$, et al. Multivariate Outcome Prediction in Traumatic Brain Injury with Focus on Laboratory Values. Journal of Neurotrauma. 2012;29(17):2613-24. Available from: http://dx.doi. org/10.1089/neu 2012.2468

50.Perel P, Wasserberg J, Ravi RR, Shakur H, Edwards $P$, Roberts I. Prognosis following head injury: a survey of doctors from developing and developed countries. EvalClin Pract2007;13:464-0005.

51.Melo JR. Acute hyperglycemia is a reliable outcome predictor in children with severe traumatic brain injury.
ActaNeurochir (Wien).2010; 152(9):1559-65

52. Rachel P. Berger, Ronald L. Hayes, Rudolph Richichi, Sue R. Beers. Serum Concentrations of Ubiquitin C-Terminal Hydrolase-L1 and all-Spectrin Breakdown Product $145 \mathrm{kDa}$ Correlate with Outcome after Pediatric TBI. J Neurotrauma.2012; 29(1): 162-167.

53. Samit M. Biochemical Serum Markers in Head Injury, Clinical Neurosurgery.2012;57:134-140.

54 . Tude M. Defenestration in children younger than 6 years old: mortality predictors in severe head trauma. Childs Nerv Syst. 2009; 25:1077-1083.

55.Mondello E. Clinical Utility of Serum Levels of Ubiquitin C-Terminal Hydrolase as a Biomarker for Severe Traumatic Brain Injury. Neurosurgery.2012;70(3):666-75.

56. Nyle K. Increased serum-GFAP in patients with severe traumatic brain injury is related to outcome. Journal of the Neurological Sciences.2006; 240.85-91. ExitusAfter Traumatic Brain Injury: Biomarker S100B 24H. Clin. Lab.2011; 57:587-597.

58. Soares L. Interleukin-10 is an Independent Biomarker of Severe Traumatic Brain Injury Prognosis. Neuroimmunomodulation. 2012;19:377-385.

59.Salehpour F, Bazzazi AM, Porhomayon J, NaderND. Correlation between coagulopathy and outcome in severe head trauma in neurointensive care and trauma units. J Crit Care. 2011;26(4):352-6.

60.Stein DM. Relationship of Serum and Cerebrospinal Fluid Biomarkers With Intracranial Hypertension and Cerebral Hypoperfusion After Severe Traumatic Brain Injury. J Trauma.2011;70(5):1096-103.

61. Nelson DW. Hierarchical log linear analysis of admission blood parameters and clinica outcome following traumatic brain injury. Neurotrauma.2012;29(17):2613-24.

62. NyleN. Serum levels of S100B, S100A1B and $\mathrm{S} 100 \mathrm{BB}$ are all related to outcome after severe traumatic brain injury. ActaNeurochir (Wien).2008;150(3):221-7.

63. Raineya T, Leskob M. Predicting outcome after severe traumatic brain injury using the serum S100B biomarker: Results using a single $(24 \mathrm{~h})$ time-point Resuscitation.2009; 341-345.

$64 . Z ̌ u r e k J$,Fedora M. The usefulness of S100B, NSE, GFAP, NF-H, secretagogin and Hsp70 as a predictive biomarker of outcome in children with traumatic brain injury. Acta Neurochir.2012; 154:93-103.

66. Els C.H. Prognosis of six-month function after traumatic brain injury. Rehabil Med.2010; 42: 425-436.

67.V. Jain, S. Tiwari, S. Misra, Tiwari, Nagendra. Predictive Value of Serum Lactate Dehydrogenase in Head Injury. The Internet Journal of Surgery. 2010 22(2):101-110.

68.Barlow P, Teasdale G. Prediction of outcome and the management of severe head injuries: the attitudes of neurosurgeons. Neurosurg.1986; 19:989-991.

69. Gong D, Hao M, Liu L, Liu C, Dong J, Cui Z, et al. Prognostic relevance of circulating endothelial progenito cells for severe traumatic brain injury. Brain Inj. Inform Healthcare. 2012;26(3):291-7. Available from: http:/l dx.doi.org/10.3109/02699052.2011.648710

70. Oliviera D. Plasma von Willebrand Factor Levels Correlate with Clinical Outcome of Severe Traumatic Brain Injury. Journal of neurotrauma.2007; 24:13311338.

71. Papa L. Serum levels of ubiquitin C-terminal hydrolase distinguish mild traumatic brain injury from trauma controls and are elevated in mild and moderate traumatic brain injury patients with intracranial lesions and neurosurgical intervention. J Trauma Acute Care Surg.2012; 72(5):1335-44.

72. WhaSookSeo, HyunSoo Oh. Comparisons of Acute Physiological Parameters Influencing Outcome in Patient with Traumatic Brain Injury and Hemorrhagic Stroke. Worldviews Evid Based Nurs.6(1):36-43;2009.

73.Prisco L, Iscra F, Ganau M, Berlot G.Early predictive factors on mortality in head injured patients: a retrospective analysis of 112 traumatic brain injured patients. J Neurosurg Sci. 2012 Jun;56(2):131-6. 


\section{Comments}

The authors of this study included 63 reports including patients with 'different levels of TBI' and their 'outcome measure has been GCS after 6 months'. Even though design of this systematic review can bring up some information for the readers but there are issues important to be stressed regarding further similar future reviews; a) The question about different humoral factors effective upon the outcome of TBls is an old issue for neurosurgeons treating emergency cases. A systematic review evaluating these elements is better to include prior publications with similar power-level from the literature and not only the bank of 8 years duration. b) For a systematic review to be of good conclusive remark, the studies with higher level of evidence and not, only cohort studies should be included in the chart. If there has been no such reports available, the power of the review would be low regarding the biases and threats to the validities and interpretation of the results. These errors are the results of flaw in either the method of selection of the studies or the procedures undertaken in gathering, interpreting and including the measures and/or disease information. c) To obviate the concordance of interpretation of information, the first step would be drawing the flow chart (lacking in this report). To evaluate the possible inter-observer errors in a limited sample of cases, drawing the chart to measure the Kappa index (also lacking here) is helpful. Including a 'Prisma' model to coordinate between entry point, case management process and functional outcome is another way to empower a systematic review. d) A systematic review can be summarized in a 'funnel chart' till the readers could beware of the level of similarity/ concordance of the data extracted from all the references in a glance (lacking). e) Including all the levels of TBI in a systematic review includes quite a very large heterogeneous group of patients with all dissimilarities of the pathophysiological changes both in CNS and in the immune responses. Evaluating all the possible factors with or without independent and confounding impact upon a single outcome variable, can be very hard both for statistical analysis and for scientific interpretation of the results. f) For discussing a systematic review, it is not enough to select a single variable and highlight the points drawn from data extracted from a large table ( as it is included) but the most empowered and proven variables are better to be discussed only, otherwise misclassification of the information (regarding exposure and outcome categories) would be a common error. Anyhow, the kind researchers have done a great job preparing this excellent review for our readers, even though it wold be better to name it a 'narrative review of the literature'

Kazem Abbassioun, MD, Professor of Neurosurgery,
Vice-president of Iranian Association of Surgeons, Tehran, Iran

Firooz Salehpoor and colleagues showed that based on a systematic review there is strong evidence for predicting poor prognosis for six-month outcome of moderate and severe traumatic brain injury (TBI) for the high serum concentration of S100/S100B protein (17 out of 19 studies), neuron specific enolase (NSE: 9 out of 12 studies), myelin basic protein (MBP: 2 out of 2 studies in childhood), Hyperphosphorylated neurofilament (NF-H: 2 out of 2 studies in childhood), Glial Fibrillary Acidic Protein (GFAP: 7 out of 7 studies), Ubiquitin C-Terminal Hydrolase (UCHL1: 4 out of 5 studies), blood glucose levels (19 out of 22 studies), Lactate Dehydrogenase (LDH: 2 out of 2 studies), admission/increasing serum osmolarity (high sodium: 2 out of 2 studies), prothrombin time ( PT: 5 out of 5 studies), partial thromboplastin time (PTT: 2 out of 3 studies), Heat Shock Protein 70 (HSP 70: 2 out of 2 studies), serum levels of interleukin (IL)-8 (2 out of 2 studies), increased circulating cell-free DNA levels (DNA: 2 out of 2 studies) (1). They found two more strong evidence of decreased platelet count (2 out of 3 studies), and decreased number of circulating endothelial progenitor cells (EPCs: 2 out of 2 studies) in poor outcome of TBI patients. They stated moderate evidence for high serum MMP9 levels as a marker of poor outcome prediction for TBI. On the other hand, there was no relation between D-dimer level and poor outcome of moderate and severe TBI in the available two studies. I would acknowledge their extensive study and the importance of their study design. I believe the systematic reviews have high impact in promotion of science and literature. However, there are several important concerns in their study: Assessing quality and susceptibility to bias is essential when interpreting primary research and conducting systematic reviews for observational epidemiological studies such as cohort studies (2). The recommended tool is STROBE guidelines for reporting observational epidemiological studies (3). For each included study in the systematic review of cohort studies, we have to perform quality assessment which has to be done based on the STROBE guideline not based on the consensus. It is the main difference between systematic review and narrative review. In the systematic review, any researcher can use guideline and evaluate if any study has high or low quality. However, in narrative review, an expert or a few experts perform their judgement based on the experience not based on the evidence. There are 22 items (the STROBE Statement) that relate to the title, abstract, introduction, methods, results, and discussion sections of articles. 18 items are common to all three study designs and four are specific for cohort, case-control, or cross-sectional studies. Our readers need to know if in each included cohort, did authors state the eligibility criteria, and the sources and methods of selection of participants; describe methods of follow-up? For matched studies, did they give matching criteria and number of exposed and unexposed? If applicable, did they explain how loss to follow-up was addressed? Did authors summarize follow-up time (average and total amount)? Did they report numbers of outcome events or summary measures over time? Did they give unadjusted estimates and, if applicable, confounder-adjusted estimates and their precision (e.g., 95\% confidence interval)? Did they make clear which confounders were adjusted for and why they were included? Did they report category boundaries when continuous variables were categorized? If relevant, did they consider translating estimates of relative risk (RR) into absolute risk for a meaningful time period? Did they perform analyses of subgroups and interactions, and sensitivity analyses? Did they summarize key results with reference to study objectives? Did they discuss limitations of the study, taking into account sources of potential bias or imprecision? Did they discuss both direction and magnitude of any potential bias? Did authors give a cautious overall interpretation of results considering objectives, limitations, multiplicity of analyses, results from similar studies, and other relevant evidence? Did they discuss the generalisability (external validity) of the study results? Did they give the source of funding and the role of the funders? Authors mentioned databases were searched from 2005 to 2014. There is no included paper in 2014 and the standard in systematic review is to write the exact date or month (not year) of systematic review (4). There is no flow diagram of studies based on the PRISMA statement; therefore we do not know how many papers selected from each database; and how many duplicates were removed; how many abstracts were screened; how many and why full papers were excluded. Finally, I would suggest the following title for this so called systematic review: A non quality assessed literature review of serum markers for moderate and severe traumatic brain injury based on the published papers from 2005 to 2013.

Vafa Rahimi-Movaghar, MD, Professor of Neurosurgery, Sina Trauma and Surgery Research Center, Tehran University of Medical Sciences, Tehran, Iran

Reference:

1. Salehpoor F, Meshkini A, Shokouhi Gh, Aghazade J, Lotfinia Shakeri M, et al. Prognostic Serum Factors in Traumatic Brian Injury: A Systematic Review. IrJNS. 2015;1(1):10-22.

2. Sanderson S1, Tatt ID, Higgins JP. Tools for assessing quality and susceptibility to bias in observational studies in epidemiology: a systematic review and annotated bibliography. Int J Epidemiol. 2007;36(3): 666-76.

3. von Elm E1, Altman DG, Egger M, Pocock SJ, Gøtzsche PC Vandenbroucke JP; STROBE Initiative. The Strengthening the Reporting of Observational Studies in Epidemiology (STROBE) Med. 2007:4 (10):e296.

4. Rasouli MR1, Rahimi-Movaghar V, Shokraneh F, MoradiLakeh M, Chou R. Minimally invasive discectomy versus 